\begin{tabular}{|c|c|}
\hline Citation & $\begin{array}{l}\text { Sander Deridder, Wim Smits, Ken Broeckhoven, Gert Desmet (2020), } \\
\text { A multiscale modelling study on the sense and nonsense of thermal } \\
\text { conductivity enhancement of liquid chromatography packings and other } \\
\text { potential solutions for viscous heating effects } \\
\text { Journal of Chromatography A, } 1620,461022 \text {. }\end{array}$ \\
\hline Archived version & $\begin{array}{l}\text { Author manuscript: the content is identical to the content of the } \\
\text { published paper, but without the final typesetting by the publisher }\end{array}$ \\
\hline Published version & https://doi.org/10.1016/j.chroma.2020.461022 \\
\hline Journal homepage & https://www.journals.elsevier.com/journal-of-chromatography-a \\
\hline Author contact & $\frac{\text { sander.deridder@kuleuven.be }}{+3215688147}$ \\
\hline
\end{tabular}

(article begins on next page) 


\title{
A Multiscale Modelling Study on the Sense and Nonsense of Thermal Conductivity Enhancement of Liquid Chromatography Packings and Other Potential Solutions for Viscous Heating Effects
}

\author{
Short: Sense and Nonsense of Thermal Conductivity Enhancement in Liquid Chromatography
}

Sander Deridder, Wim Smits, Ken Broeckhoven, Gert Desmet ${ }^{(*)}$

Vrije Universiteit Brussel, Pleinlaan 2, 1050 Brussel, Belgium

${ }^{(*)}$ Corresponding author: email: gedesmet@vub.be

tel.: ++3226293251

fax.: ++3226293248

Declarations of interest: none

\begin{abstract}
We report on a numerical study of the thermal conductivity and temperature distribution in analytical packed bed and monolithic HPLC columns to assess the feasibility of a number of potential solutions to the viscous heating problem that would normally impede high efficiency separations when moving to extreme operating pressures (e.g., 2500 bar). Computational fluid dynamic (CFD) simulations were employed to study heat transfer on three hierarchical levels of the column: meso-pore level, through-pore level and column level. At the first level, realistic values were determined for the conductivity of the porous zone ( $\left.k_{p z}\right)$, depending on the internal structure of the porous zone and the mobile phase used (acetonitrile, water or a mixture of both). These $k_{p z}$-values were in turn used at the second level to determine realistic values for the effective conductivity of the bed $\left(k_{\text {eff }}\right)$. It was shown that the presence of a solid core only has a minor effect on the packed bed conductivity. Using highly conducting materials as core material can be expected to maximally lead to a $60 \%$ increase in bed conductivity. Contrarily, in monolithic beds, the presence of a core material would form one continuous phase of highly conducting material, thus greatly enhancing the conductivity of the bed. At the third level, the temperature field in the entire column (bed and column housing) was resolved for three typical boundary conditions: isothermal, adiabatic and still-air oven. The effect of different physical properties (inlet pressure, mobile phase composition, bed conductivity, wall conductivity and column ID) on these temperature fields was investigated. It was shown that, theoretically, besides $1 \mathrm{~mm}$ ID columns also "core-shell monoliths" can provide a solution to viscous heating (by increasing the bed conductivity). Other possible solutions are proposed and discussed.
\end{abstract}

Keywords: viscous heating; thermal conductivity; Computational Fluid Dynamics; core-shell particles; UHPLC; high pressure 


\section{Introduction}

To decrease analysis time and improve separation performance, a reduction in particle size is the most straightforward method in liquid chromatography. However, to operate sufficiently long columns packed with these smaller particles (sub-2 $\mu \mathrm{m}$ ), increased operating pressures are required. For a fixed column length and flow rate, pressure drop increases with the inverse particle size squared $\left(1 / d_{p}{ }^{2}\right)$. When working at the optimal velocity, which increases with $1 / d_{p}$, the pressure increase is even proportional to $1 / d_{p}{ }^{3}$. The much larger operation pressure in current state-of-the-art ultra-high performance LC instruments (12001500 bar), requires to consider the thermal effects that result from pumping a liquid through a porous medium. This so-called viscous heating or viscous dissipation of the mechanical energy increases the temperature $T$ of the mobile phase, column bed and hardware (wall, fittings, frits). The heat either exits the column at its outlet (giving rise to axial temperature gradients) or through its wall (giving rise to radial temperature gradients) ${ }^{[1-7]}$. In the limiting cases, all generated heat is either stored in the liquid (perfectly adiabatic conditions, large axial temperature gradient), or removed through the wall (perfectly isothermal column wall, large radial temperature gradient) ${ }^{[4,5,7]}$. Under practical LC conditions, where the column hangs in a thermostatted compartment filled with air, the thermal boundary conditions will fall in between these limiting cases, resulting in both axial and radial temperature gradients, with their amplitude depending on the flow conditions around the column (still or forced air oven). For a fixed operating pressure, the amplitude of the axial gradient depends mainly on the employed solvent (heat capacity), whereas the radial gradients depend on the square of the column radius, the flow rate and effective thermal conductivity $k_{\text {eff }}$ of the column bed (particles + inter- and intra-particle mobile phase). The effects of viscous heating can strongly be reduced by using capillary columns ${ }^{[8]}$ however, in practice, standard column formats $(2.1-4.6 \mathrm{~mm})$ still account for the vast majority of the LC market ${ }^{[9]}$. A considerable amount of work has already been done in literature concerning the potential solutions to this viscous heating problem. However, most of these studies used a theoretical model (Zarichnyak) to estimate the thermal conductivity of the packed bed. A recent computation fluid dynamics study from our group showed this model is invalid for core-shell particles under the conditions prevailing in liquid chromatography ${ }^{[10]}$. These simulations also showed that one of the previously proposed solutions, i.e. the use of core-shell particles with a super-conducting core, cannot be expected to give more than a 50 to $60 \%$ increase of the thermal bed conductivity, even when using core materials such as cupper or gold which have a conductivity that is orders of magnitudes larger than silica.

In the present study, we use the same computation fluid dynamics approach to assess the level of bed conductivity enhancement that would be needed to keep the axial temperature increase and the radial temperature gradients within affordable limits when contemplating the use of pressures exceeding the currently available maximal commercial instrumentation pressure, i.e. in the range of 2000-2500 bar. In addition, we also address the question whether the required enhancement is feasible or conceivable with existing materials or column fabrication procedures. 
For this purpose, a numerical heat transfer simulation study was conducted at three hierarchical levels:

i) meso-pore level

ii) through-pore level (=packing level)

iii) column level

The simulations at the meso-pore level are conducted to first determine the effective heat conductivity $\left(k_{p z}\right)$ of meso-porous silica, which is the material used in the vast majority of the currently employed chromatographic media (particles, silica monolith). To represent the microscopic details of the silica backbone making up the meso-porous materials, two general classes of non-porous solid phase structures were considered: i) consolidated packings of contacting spheres and ii) sponge-like monolithic skeletons. The first class represents the type of meso-porous materials obtained by agglomerating smaller nanospheres. The second group is used to represent the type of meso-porous materials obtained via spinodal decomposition sol-gel processes. In the packed sphere case, a variety of different packing geometries is possible (face-centered cubic (fcc); body-centered cubic (bcc); simple cubic (sc); random sphere packing, see Figs. 1a-d). In each of these packing arrangements, the packing density (generally described using the porosity $\varepsilon$ ) is fixed by the requirement that the particles need to be in contact with each other in order to form a stable material. In the monolithic skeleton case, the porosity $\varepsilon$ can, at least conceptually, be chosen as an independent variable. To represent this type of geometry, we used the Tetrahedral Skeleton Model (TSM) introduced by our group in ${ }^{[11]}$, based upon a unit cell mimicking the tetrahedral bonding structure in a diamond lattice. By varying the width and length of the skeleton branches, this geometry can represent a very wide range of porosities, including the typical value of $\varepsilon=0.6$ to 0.65 of most underivatized silica-gel materials. To broaden the range of investigated geometries, we also considered the case of the co-called inverted TSM, wherein the solid and liquid regions of the standard TSM are swapped.

In the second part of the study, targeting the macroscopic packing level, the effective conductivities of the meso-porous media obtained in the first part are combined with the effective conductivity of the mobile phase mixtures typically employed in liquid chromatography to calculate the overall thermal conductivity $\left(k_{\text {eff }}\right)$ of the chromatographic bed. This is done in the absence as well as in the presence of an interstitial flow. We also considered both fully porous and core-shell chromatographic media, as well as both particulate beds and monolithic skeleton beds. In case of a monolithic bed, the "core shell" case consists of a fully solid skeleton (the core) covered uniformly with a layer of meso-porous material.

In the third part of the study, the keff-values obtained in part two are used in a whole-column model to calculate the steady-state radial and axial thermal gradients one can expect in a typical metal-tube based commercial chromatographic column for UHPLC (dimensions $2.1 \times 50 \mathrm{~mm}$ ) for the three "classic" thermal boundary conditions (isothermal, adiabatic and still-air oven) and for varying degrees of the thermal conductivity of the packing material. This allows to quantify which magnitude of thermal conductivity (and hence also which type of materials) would be needed to keep the thermal gradients within affordable limits when considering running columns at pressures in the 2000 to 2500 bar range. Next to an increase 
of the bed conductivity, a number of other potential solutions to alleviate the viscous heating temperature gradients are discussed as well.

\section{Numerical methods}

\subsection{Geometries and grid}

Fig. 1 shows all geometries used for the conductivity simulations at the meso-pore and through-pore level. The column geometry (including detailed dimensions) used in the third part of the study can be readily viewed from temperature contour plots shown in Fig. 7 further on. These dimensions were determined by measuring a number of widely used commercial columns and rounding the resulting average value. Furthermore, some small simplifications of the actual design (e.g. the assumption of cylindrical symmetry for the column end-fitting pieces) were made as a compromise between required computational effort and gain in extra information.

In all considered spherical core-shell materials, a relative core radius $\rho=0.63$ was used. This yielded a volume fraction of shell material of 0.75 . For the tetrahedral skeleton a relative core radius $\rho=0.45$ was used. This yields the same volume fraction of shell material of 0.75 in the $\varepsilon_{\mathrm{e}}=0.60$ case and a slightly different fraction (0.73) in the $\varepsilon_{\mathrm{e}}=0.39$ case.

On the meso-pore and packing level, all ordered sphere packings contained at least $8.5 \times 10^{5}$ cells. All TSM geometries contained at least $1.9 \times 10^{6}$ cells. Both types of geometries were meshed with mainly tetrahedral cells, and inflation was used to ensure smaller, triangular prism shaped cells near the core/shell interface and shell/liquid interface as here the highest velocity and temperature gradients occur. The sizing of the mesh cells was such that quadrupling the number of cells had an impact of less than $0.1 \%$ on the measured effective conductivity.

"The random packing contained $3.2 \times 10^{6}$ tetrahedral cells, resulting in $2.4 \times 10^{3}$ cells per particle. Cells sizes were smallest near the interfaces. As a grid check, the SC packing was meshed with the same settings as the random packing (also yielding $2.4 \times 10^{3}$ cells per particle) and used with some typical material conductivities, resulting in a maximal error on the effective conductivity of $1.2 \%$."[10]

On the column level, all geometries were meshed with at least 220.000 rectangular cells. In the packed bed, smaller cells were used (as compared to the column wall and end fittings) to accurately calculate the velocity profile and cells were smaller in the radial direction (as compared to the axial direction), because in this direction velocity and temperature gradients are higher. Inflation was used to ensure smaller cell sizes near the bed/column wall interface, because in this region the highest velocity and temperature gradients are present. Halving the cell size in both axial and radial direction led to a change in the reported temperature differences $\left(\Delta \mathrm{T}_{\text {rad, bed, }} \Delta \mathrm{T}_{\mathrm{ax}, \mathrm{bed}}, \Delta \mathrm{T}_{\mathrm{ax}, \mathrm{col}}\right.$, see later) of less than $0.2 \%$. 


\subsection{Simulation procedures}

Simulations of the effective conductivity at the meso-pore and through-pore level were carried out using the same steady-state method described and accurately validated in ${ }^{[10]}$. In brief, the energy equation (which describes the conservation of energy principle) ${ }^{[12]}$ was solved using the finite volume solvers of Ansys Fluent to find the steady-state temperature field resulting from two opposite boundaries at constant, but different temperature. This allows reporting the heat flux through the geometry. The analytical solution (derived from Fourier's heat transfer law) describing the heat flux through an infinitely wide slab of finite thickness and consisting of a homogeneous material with thermal conductivity keff was used to find the value of $k_{\text {eff }}$ that correctly predicts this reported heat flux.

Simulations of the temperature distribution at the column level were carried out under steady-state conditions as well. Conservation equations for mass and momentum (to solve the velocity field) were solved together with the equation for energy conservation (to solve the temperature field). All equations were solved simultaneously because the velocity and temperature field are coupled (through viscous heating and through the temperature dependency of density and viscosity).

Liquid viscosity was put at Newtonian. The velocity fields were obtained by solving the Navier-Stokes equations using the coupled pressure-based steady state solver with a Least-Squares Cell-Based gradient evaluation and a second order upwind interpolation scheme for the momentum and second order for pressure. All velocity profiles were calculated by imposing a fixed pressure at the inlet and outlet. Temperature fields were obtained using a second-order upwind spatial discretization. Spatial gradients were again evaluated using the Least-Squares Cell-Based method. The meshing density was typically on the order of 800 cells $/ \mathrm{mm}^{2}$.

Pressure inlet and pressure outlet boundary conditions were used, with a range of different inlet pressures, while the outlet pressure was fixed at $1 \mathrm{~atm}$. The mobile phase inlet temperature was 298.15 $\mathrm{K}$. The base of the column geometry was assigned an axisymmetric boundary condition. This makes that this 2D geometry behaves as a 3D geometry with cylindrical symmetry. At the interface between the fluid zone and capillary or column wall (subsequently in the inlet capillary, cone, frit, packed bed, frit, cone and outlet capillary) a no slip boundary condition was used. All capillary and column walls were assigned the properties of stainless steel $(\mathrm{k}=16.3 \mathrm{~W}(\mathrm{~m} . \mathrm{K}))$. At the outer boundaries of the capillaries and column wall three different thermal boundary conditions were used: adiabatic boundary conditions to mimic a perfectly insulated column, isothermal boundary conditions ( $T_{\text {wall }}=298.15 \mathrm{~K}$ ) to mimic a perfectly thermostatted column and natural convection boundary conditions ( $T_{\text {room }}=298.15 \mathrm{~K}$ ) to mimic a still-air oven. Natural convection coefficients were calculated according to Eq. 10 from Churchill and Chu (1975) [13].

Three different liquids were used as mobile phase: pure water $\left(\mathrm{H}_{2} \mathrm{O}\right)$, pure acetonitrile $(A C N)$ and a $40 / 60(v \% / v \%) \mathrm{ACN} / \mathrm{H}_{2} \mathrm{O}$ mixture. Density and viscosity of these liquids as a function of temperature and 
pressure were taken from National Institute of Standards and Technology (NIST) database in case of water and from Billen et al. ${ }^{[14]}$ in case of $\mathrm{ACN}$ and the $\mathrm{ACN} / \mathrm{H}_{2} \mathrm{O}$ mixture. Data was fitted to provide the solver with a continuous function of pressure and temperature. In ${ }^{[14]}$ data is only reported for pressures up to $1000 \mathrm{bar}$, hence for higher pressures these data were extrapolated. The expansion coefficient $\alpha(p, T)$ was calculated from these fitted functions as:

wherein $\rho$ is the density of the liquid. Thermal conductivity $(k)$ and isobaric heat capacity $\left(C_{p}\right)$ were taken at constant $\mathrm{p}$ (1 bar) and $\mathrm{T}(298.15 \mathrm{~K})$.

\begin{tabular}{|c|c|c|}
\hline Mobile phase liquid & $k[W /(m . K)]$ & $\mathrm{C}_{\mathrm{p}}[\mathrm{J} /(\mathrm{kg} . \mathrm{K})]$ \\
\hline $\mathrm{H}_{2} \mathrm{O}$ & $0.61^{(1)}$ & $4181.3^{(1)}$ \\
\hline $\mathrm{ACN}$ & $0.19^{(2)}$ & $2233.6^{(3)}$ \\
\hline $40 / 60(v \% / v \%)$ ACN/ $\mathrm{H}_{2} \mathrm{O}$ & $0.41^{(4)}$ & $3785.8^{(3)}$ \\
\hline \multicolumn{3}{|l|}{ NIST } \\
\hline \multicolumn{3}{|l|}{ Hulse et al., 2004. ${ }^{[15]}$} \\
\hline \multicolumn{3}{|c|}{ Kolker and Safonova, $2010^{[16]}$. In case of the mixture, the $C_{p}$ value was determined by linear } \\
\hline \multicolumn{3}{|c|}{ By interpolation between pure $\mathrm{H}_{2} \mathrm{O}$ and $\mathrm{ACN}$, according to Jamieson et al. ${ }^{[17]}$ with $\alpha=1$. } \\
\hline
\end{tabular}

While the mobile phase is 'pushed' through the system, energy originating from the effected pressure work is dissipated in the system. Part of it is absorbed during the expansion of the mobile phase liquid, while the remainder leads to the heating of the mobile phase liquid. Eq. (2) gives the pressure work done per unit of time per unit of volume (W) in an infinitesimal control volume in cylindrical coordinates.

$$
\begin{aligned}
W & =\left(\frac{\partial\left(u_{x} P\right)}{\partial x}+\frac{1}{r} \frac{\partial\left(r u_{r} P\right)}{\partial r}\right) \\
& =\left(u_{x} \frac{\partial P}{\partial x}+P \frac{\partial u_{x}}{\partial x}+P \frac{\partial u_{r}}{\partial r}+u_{r} \frac{\partial P}{\partial r}+\frac{P u_{r}}{r}\right)
\end{aligned}
$$

In which $\mathrm{P}$ is the local pressure and $\mathrm{u}_{\mathrm{x}}$ and $\mathrm{u}_{\mathrm{r}}$ the axial and radial velocity components.

This pressure work term multiplied with $\alpha \mathrm{T}$, in which $\alpha$ is the thermal expansion coefficient, gives the amount of energy absorbed by the thermal expansion and hence the remaining energy, available for heating is ${ }^{[7,18]}$ :

$$
\left(u_{x} \frac{\partial P}{\partial x}+P \frac{\partial u_{x}}{\partial x}+P \frac{\partial u_{r}}{\partial r}+u_{r} \frac{\partial P}{\partial r}+\frac{P u_{r}}{r}\right)(1-\alpha T)
$$


A user defined function (UDF), that allows to incorporate this expression in the energy balance as an extra energy source term was used.

All simulations were performed with the finite volume solvers of Ansys Fluent, version 17.1 from Ansys, Inc. This software was used on Dell Power Edge R210 RackServers each equipped with an Intel Xeon x3460 processor (clockspeed 2,8 GHz, 4 cores) and $16 \mathrm{~Gb}, 1333 \mathrm{MHz}$ ram memory and Windows server edition 2008 R2 (64-bit) as operating system.

\section{Results and discussion}

\subsection{Simulations at the meso-pore level}

In this section, heat conductivity simulations were carried out at the meso-pore level, considering binary media consisting of an impermeable silica network (the silica backbone) whose interstices are filled with a liquid medium (the mobile phase zone) as depicted in Fig. 1. The obtained conductivity values represent the effective conductivity $k_{p z}$ of the meso-porous zone in silica materials when filled with the mobile phase liquids typically used in LC. Given the thermal conductivity of alkyl chains $/ C_{18}\left(k_{c 18}=0.15 \mathrm{~W} /(\mathrm{m} . \mathrm{K})\right)$ is not too different from that of the typical mobile phases being used in chromatography (typically ranging between $\mathrm{k}_{\mathrm{m}}=0.61 \mathrm{~W} /(\mathrm{m} . \mathrm{K})$ for pure water and $0.19 \mathrm{~W} /(\mathrm{m} . \mathrm{K})$ for pure $\left.A C N\right)$, and given that in most cases the alkyl chains anyhow make up only a fraction of the stationary phase layer, the latter is assumed to be an integral part of the mobile phase zone.

Fig. 2 shows how the obtained effective conductivity curves monotonically decrease with increasing $\varepsilon$. This increase can be understood as a direct consequence of the fact that an increase in $\varepsilon$ inherently implies a decrease of the fraction of silica and the fact that silica has a markedly larger conductivity $\left(\mathrm{k}_{\mathrm{SiO}_{2}}=1.40\right.$ $\mathrm{W} /(\mathrm{m} . \mathrm{K}))$ than the mobile phase.

It can also be noted that the effective conductivity curves shift upwards when the conductivity of the mobile phase $\left(\mathrm{k}_{\mathrm{m}}\right)$ increases. This increase is less than linearly proportional because the mobile phase only makes up part of the material. For the same reason (effect of $\mathrm{k}_{\mathrm{m}}$ is damped by presence of silica material), it is obvious to observe the effect of $k_{m}$ is smallest in the structures with the lowest external porosity $\varepsilon$ and gradually becomes larger when $\varepsilon$ increases, i.e., with increasing fraction of mobile phase.

Another observation from Fig. 2 is that the geometrical details of the structure have a smaller effect than the porosity. For the TSM and inverted TSM-models, this even holds to such an extent that both structures produce nearly perfectly overlapping curves (cf. black solid and open symbols). The difference between the tetrahedral skeleton structures (connected black data points) and the sphere packings (isolated blue and red data points) is also relatively small, reducing to virtually nothing when the mobile phase conductivity is large (blue data points nearly coincide perfectly with the black data point curves for the case of $\left.k_{m}=0.58 \mathrm{~W} /(\mathrm{m} . \mathrm{K})\right)$. Not surprisingly, the $\mathrm{k}_{\mathrm{m}}=0.58$-case is the one where the geometrical details matter least, as this is also the case where the difference in conductivity between the solid and liquid 
phase is smallest. When the mobile phase conductivity is small (cf. position of red data points with respect to black data points for $\left.\mathrm{k}_{\mathrm{m}}=0.21 \mathrm{~W} /(\mathrm{m} . \mathrm{K})\right)$, the particulate bed geometry produces effective conductivity values that are about $10-15 \%$ lower than the tetrahedral skeleton. This effect can be owed to the higher degree of connectivity in the tetrahedral structure as opposed to the limited contact area between the individual particles in the consolidated particle packing.

\subsection{Simulations at the packing and through-pore level}

Moving up one level, the present section considers the effective heat transfer occurring at the level of the interstitial space and the particles (or skeleton branches in case of monolithic media). The overall conductivity calculated at this level is hence representative for the effective conductivity keff of the chromatographic bed. In these calculations, the $k_{p z}$-values obtained in the previous section are used to represent the thermal conductivity of the meso-porous zones of the particles or the skeleton branches. For the thermal conductivity of the mobile phase liquid in the interstitial space, the well-established values for water and acetonitrile are used. Both the pure liquids as well as a $40 / 60(v \% / v \%) ~ A C N / \mathrm{H}_{2} \mathrm{O}$ mixture were considered. For the sake of brevity, most presented results are for water.

First, the effect of the presence of a convective flow in the interstitial space was investigated. As can be noted from Fig. 3, the effective bed conductivity of a $2 \mu \mathrm{m}$ particle bed can only be expected to be significantly influenced by the presence of a convective heat transfer component when the fluid velocity exceeds $10 \mathrm{~cm} / \mathrm{s}$. These are values that are normally never reached in chromatography. All subsequent calculations have therefore been conducted assuming a zero velocity in the through-pores, in agreement with the assumptions made in earlier work ${ }^{[19]}$.

As already stated, Fig. 2 shows that the $\mathrm{k}_{\mathrm{pz}}$-value of a typical silica sol-gel material (for which the internal porosity before coating is around $\varepsilon=0.6$ to 0.65$)$ is typically of the order of $k_{p z}=0.5$ to $0.9 \mathrm{~W} /(\mathrm{m} . \mathrm{K})$. However, to cover the widest possible range of $k_{p z}$-values, the simulations performed in Figs. 4-5 were carried out over a range that is significantly broader $\left(0.2<\mathrm{k}_{\mathrm{pz}}<2\right)$ than is accessible with silica as the support material to offer a more general view on the relation between the $k_{\text {eff }}$ of the bed and the $k_{p z}$ of the mesoporous silica material. Fig. 4 compares the effective bed conductivity $k_{\text {eff }}$ for two sphere packing cases: a perfectly ordered one ( $\mathrm{fcc}$ packing with a porosity of $\varepsilon=0.24$, Fig. $4 \mathrm{a}$ ) and a randomly packed one (Fig. $4 \mathrm{~b}$ ) with a porosity of $\varepsilon=0.39$ as typically encountered in packed bed columns. Fig. 5 shows the keff-data for two distinct tetrahedral skeleton model cases, resp. with an external porosity of $\varepsilon=0.4$ and 0.6 . The first value was selected to enable a direct comparison with the packed bed of spheres, while the second value is more typical of actual silica monolithic beds ${ }^{[20]}$.

Considering first only the black curves (=no core) in both Fig. 4 and 5, it can be observed how $k_{\text {eff }}$ increases with increasing conductivity $\left(k_{p z}\right)$ of the packing material, as physically expected. Again, this increase is weaker than linear because the meso-porous material, i.e., the region where the variation in $k_{p z}$ is actually imposed upon, only makes up a fraction $\varepsilon$ of the total bed, while the conductivity of the mobile zone 
(remaining fraction 1- 1 ) is kept invariant at $k_{m}=0.58$. For similar reasons, it is also obvious to see that the increase of $k_{\text {eff }}$ with $k_{p z}$ is steepest for the material with the highest solid fraction (fcc with $\varepsilon=0.24$, fig. $4 a$ ) and weakest for the material with the lowest solid fraction (TSM with $\varepsilon=0.6$, fig. 5b).

On a side note, it is also interesting to observe that, in the absence of a solid core (=black data in Figs. 4 and 5), the porosity effect is significantly larger than the effect of the packing shape, as can for example be witnessed from the fact that the $\varepsilon=0.39$-packed bed and the $\varepsilon=0.39$-tetrahedral skeleton model (resp.

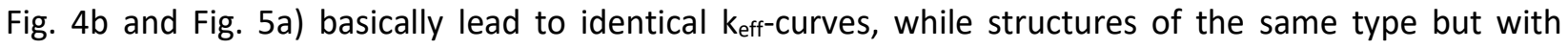
different $\varepsilon$ lead to significantly different keff-values (compare Fig. 4a with 4 b or compare Fig. $5 a$ with $5 b$ ).

The most striking observation from Figs. 4 and 5 is made when considering the data points corresponding to the presence of a non-porous, high conductivity core (=gray symbols and curves). In ${ }^{[10]}$ it was already observed and explained that the use of particles with high-conductivity cores can only be expected to have a limited effect on the overall bed $k_{\text {eff. }}$ This is confirmed again in Fig. 4, showing that, for example, the presence of a solid silica core only changes the effective bed conductivity over that of a bed of fully porous particles with some $10 \%$ to $15 \%$ in the practically relevant range of $k_{p z}$-values (ranging from 0.8 to 1.1 $\mathrm{W} /(\mathrm{m} . \mathrm{K})$ in case of water as a mobile). Even when contemplating the use of $\mathrm{Al}_{2} \mathrm{O}_{3}$ - or Cu-cores, with a conductivity that is respectively 29 and 285 times higher than that of a silica core, the increase in effective over-all bed conductivity is nowhere larger than some 50 to $60 \%$.

Whereas Fig. 4 is for pure water, we found it also instructive to investigate the changes in keff with varying core conductivity for pure $\mathrm{ACN}$ as well as for a mixture with some intermediate composition, somewhat

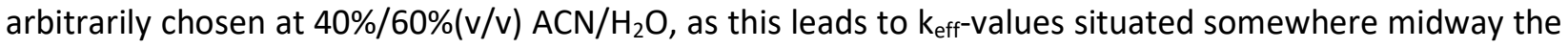
$k_{\text {eff }}$ of pure water and that of pure ACN. The results are shown in Fig. 6, again confirming maximal gains can in all three cases never be expected to become larger than some $55 \%$. The course of the three curves is nearly identical (relative plots nearly perfectly overlap, data not shown). The vertical difference between the curves can hence be fully attributed to the differences in conductivity of the mobile phase, with the highest conductivity mobile phase (pure water) producing the highest $k_{\text {eff, }}$ as physically expected.

On the other hand, the use of a high conductivity core material clearly would have a much stronger effect in the monolithic bed case (Fig. 5), as the computed keff-values are roughly one order of magnitude larger than in the core-shell particle bed cases (compare $y$-axis scale with Fig. 4). The straightforward explanation for this difference is that in the spherical particle case the high conductivity cores are isolated from each other by the less conductive shells and can hence not form an interconnected high conductivity path through the column. In the monolithic case, on the other hand, the core backbone inherently forms a fully interconnected structure, such that any higher conductivity automatically carries over the entire length of the bed. 
Comparing the $\varepsilon=0.39$ and $\varepsilon=0.6$-monolithic structures (Figs. $5 a-b$ ) shows the $\varepsilon=0.39$-case leads to higher

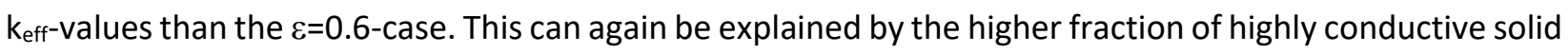
material in the $\varepsilon=0.39$-case.

\subsection{Simulations at the column level}

Finally, moving to the whole-column level to address the main research question of our study, the keff values calculated in the preceding sections are used to calculate the temperature distribution profiles that can be expected in conventional metal tubing-based $5 \mathrm{~cm}$ columns operated at pressures up to $2500 \mathrm{bar}$. Fig. 7 shows the results obtained at 2500bar for the three different considered thermal boundary conditions. In general, the temperature contour plots are very similar to the ones already obtained in literature at lower pressures ${ }^{[6,7,19,21-23]}$. They display similar shape, but higher absolute temperature values. This implies that the main effect of the higher inlet pressures employed is due to the accompanying increased viscous heating, while secondary effects resulting from the high temperatures and pressures (density and viscosity changes) do not lead to a specific deviation from the thermal behavior observed at lower pressures.

Similar to what is already well-documented for lower operating pressures ${ }^{[6,7,19,21-23]}$, the isothermal lines in a column operated at 2500 bar still substantially run in the axial direction when the column is operated in a thermostatted environment (Fig. 7a). Some small deviations from a perfect axial uniformity can be seen (mainly at the inlet of the bed), but these can essentially be attributed to entrance effects and the presence of the endfittings and the metal inlet tubing, details that were not included in earlier work. In the adiabatic case on the other hand, the isothermal lines substantially run in the radial direction (Fig. 7b), reflecting that here the temperature mainly changes in the axial direction, again in agreement with the situation at lower pressures. The small radial gradient that can be observed despite the adiabatic conditions is caused by the fact that the adiabatic wall conditions are imposed at the outer mantle of the metal tubing, leaving the possibility for an internal heat flow running from the end to the front of the column along the metal tubing ${ }^{[7]}$.

Fig. 7c shows that the overall temperature distribution under natural convection conditions (representing the practical conditions in a still-air oven) lies much closer to the adiabatic case than to the isothermal case. Since the temperature difference between the inside of the column and the environment is smaller at the start of the column, the radial temperature gradients are the smallest at the inlet and increase towards the end of the column. This is again similar to the situation observed at lower pressures ${ }^{[6,7,19,21-}$ 23].

\subsubsection{Column-level temperature gradients}


Comparing the results of all conducted whole-column simulations in a more quantitative way, Fig. 8 shows

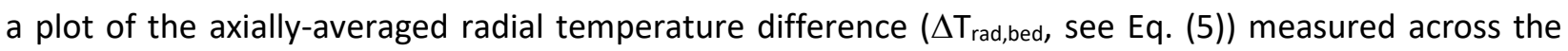
packed bed part of the column as a function of the radially-averaged axial temperature difference $\left(\Delta T_{a x, b e d}\right.$, see Eq. (4)) for different inlet pressures for the case of a 40/60 (v/v) ACN/water mixture (very similar curves are obtained for pure water and pure ACN-cases, see Fig. 1 and 2 of SM). As a side note, it should be remarked that, when changing the pressures, it was opted to keep the flow rate constant at $0.5 \mathrm{~mL} / \mathrm{min}$ (measured at column inlet). With also the column length fixed, this implies gradually decreasing column permeabilities (corresponding to ever decreasing particle sizes) are considered when the pressure was ranged from 500 to 2500 bar. Under the presently adopted conditions of a fixed bed length $\mathrm{L}=5 \mathrm{~m}$ and flow rate $\mathrm{F}=0.5 \mathrm{~mL} / \mathrm{min}$, the particle sizes corresponding to these different pressures respectively correspond to $1.53 \mu \mathrm{m}$ at $500 \mathrm{bar}, 1.22 \mu \mathrm{m}$ at $750 \mathrm{bar}, 1.04 \mu \mathrm{m}$ at $1000 \mathrm{bar}, 0.82 \mu \mathrm{m}$ at $1500 \mathrm{bar}, 0.69 \mu \mathrm{m}$ at $2000 \mathrm{bar}$ and $0.59 \mu \mathrm{m}$ at 2500 bar. Other assumptions are certainly possible, but it was considered that keeping the permeability constant would lead to flow rates that would become impractically large when reaching the highest pressures. Higher pressures can obviously also be used to make longer columns, but in that case the viscous heating problem is less important ( $F$ decreases with increasing $L$ and consequently the amount of produced heat $\mathrm{Q}=\mathrm{F} . \Delta \mathrm{P}$ decreases).

In Fig. 8a, $\Delta \mathrm{T}_{\text {rad,bed }}$ is plotted versus the axial temperature difference between the column in- and outlet $\left(\Delta \mathrm{T}_{\mathrm{ax}, \mathrm{col}}\right)$. This is the axial temperature increase measure that is experimentally most easily obtained (by inserting a thermocouple in the in- and outlet stream of the column) and therefore used in many studies on viscous heating. In Fig. 8b, the $x$-axis coordinate represents the axial temperature establishing over the packed segment of the column only $\left(\Delta \mathrm{T}_{\mathrm{ax}, \mathrm{bed}}\right)$. This is the chromatographically more relevant measure, and will hence be used in the remainder of the study. Since the temperature in the bed varies with both the axial and radial position, it should be noted that the reported $\Delta \mathrm{T}_{\mathrm{ax}, \text { bed }}$ was calculated by taking the difference between the average (mixing cup) temperature at the bed inlet and outlet and $\Delta \mathrm{T}_{\text {rad,bed }}$ by taking the average along the total bed length of the temperature difference between the center and outer region of the bed.

$$
\begin{aligned}
& \Delta T_{\text {ax,bed }}=\bar{T}_{\text {bed,out }}-\bar{T}_{\text {bed,in }}=\frac{\int_{S_{\text {bed,out }}} \rho \cdot C_{p} \cdot T \cdot u \cdot \varepsilon \cdot d S}{\int_{S_{\text {bed,out }}} \rho \cdot C_{p} \cdot u \cdot \varepsilon \cdot d S}-\frac{\int_{S_{\text {bed,in }}} \rho \cdot C_{p} \cdot T \cdot u \cdot \varepsilon \cdot d S}{\int_{S_{\text {bed }}, \text { in }} \rho \cdot C_{p} \cdot u \cdot \varepsilon \cdot d S} \\
& \Delta T_{\text {rad,bed }}=\frac{\int_{0}^{L}\left(T_{\text {axis }}-T_{\text {wall }}\right) \cdot d x}{L}
\end{aligned}
$$

With, $\bar{T}$ the mixing cup temperature, $\rho$ the density, $C_{p}$ the heat capacity, $u$ the $x$-velocity, $\varepsilon$ the bed porosity, $S$ the cross sectional area of the bed, $L$ the length of the bed, $T_{\text {axis }}$ the temperature at the axis of the bed and $T_{\text {wall }}$ the temperature at the interface between bed and column wall. 
First considering the plots of $\Delta \mathrm{T}_{\text {rad, bed }}$ versus $\Delta \mathrm{T}_{\mathrm{ax}, \mathrm{col}}$ (Fig. 8a), the isothermal boundary condition case clearly leads to the physically expected behavior: no significant change in temperature along the $x$-axis, while the radial temperature difference across the bed consistently increases with increasing pressure. Hence the near-perfectly vertical progression of the data points. The adiabatic boundary condition on the other hand produces the strongest axial temperature increase while the radial T-gradient is smallest. However, and despite what is physically expected for an adiabatically insulated system, the $\Delta T_{\text {rad,bed-values are not }}$ negligible and steadily increase with increasing pressure. This is due to the already mentioned heat backflow in the metal column mantle. This backflow establishes because in practice the adiabatic wall condition can only be applied on the outer wall of the metal tubing, such that part of the heat can still radially escape from the chromatographic bed region. The natural convection case shows a behavior that is very similar to the adiabatic case, but with a $\Delta \mathrm{T}_{\text {rad,bed }}$ versus $\Delta \mathrm{T}_{\mathrm{ax}, \mathrm{col}}$-relationship that has a roughly twofold higher slope. In both cases (natural convection and adiabatic), the relationship between $\Delta T_{\text {rad,bed }}$ and $\Delta T_{a x, \text { col }}$ is close to linear.

Comparing Fig. 8a with Fig. 8b, where the x-axis represents $\Delta \mathrm{T}_{\mathrm{ax}, \text { bed }}$ instead of $\Delta \mathrm{T}_{\mathrm{ax}, \mathrm{col}}$, it readily becomes apparent that the axial temperature differences across the bed $\left(\Delta \mathrm{T}_{\mathrm{ax}, \mathrm{bed}}\right)$ are considerably smaller than those measured across the entire column, with roughly $\Delta \mathrm{T}_{\mathrm{ax}, \mathrm{bed}} \cong 60 \%$ of $\Delta \mathrm{T}_{\mathrm{ax}, \mathrm{col}}$. Or in other words, about $40 \%$ of the measured temperature increase occurs in the metal endfitting pieces. This shows the reduction in retention caused by the viscous heating is significantly less than one would expect when determining the axial temperature increase by inserting thermocouples in the in- and outlet flow. Taking the case represented in Fig. $8\left(40 / 60 \mathrm{ACN} / \mathrm{H}_{2} \mathrm{O}\right.$ mixture, $\left.\mathrm{F}_{\text {in }}=0.5 \mathrm{~mL} / \mathrm{min}, \mathrm{L}=5 \mathrm{~cm}\right)$, the axial temperature across the bed itself would be limited to some $18^{\circ} \mathrm{C}$ at 2500 bar under still air conditions (=natural convection), rather than the $32^{\circ} \mathrm{C}$ measured across the column. Taking a typical retention enthalpy of $7,5.10^{3} \mathrm{~J} / \mathrm{mol}$ this corresponds to a decrease in retention between front and end of the bed of some $15 \%$, whereas the across-column temperature difference would one make to assume a $25 \%$ loss in retention capacity between in- and outlet. Although the course of the curves in Fig. $8 \mathrm{~b}$ is very similar to those in Fig. $8 \mathrm{a}$, they show a distinct upward curvature, as the values on the $y$-axis are the same as in Fig. $8 \mathrm{a}$, where $\Delta \mathrm{T}_{\mathrm{ax}, \mathrm{col}}$ increseases almost linearly with $\Delta \mathrm{P}$, but $\Delta \mathrm{T}_{\mathrm{ax} \text {,bed }}$ increases slower (due to an increasing fraction of the removed heat being lost in the large surface area column endfittings). Plotted versus $\Delta T_{a x, b e d}$, the isothermal case now also displays a small axial temperature difference. This temperature increase is eliminated in $\Delta T_{a x, c o l}$ as this heat is lost in the narrow outlet tubing due to conduction to the column endfitting.

Whereas the data shown in Fig. 8 were for a 40/60 ACN/water mixture, it should be noted the slope of the

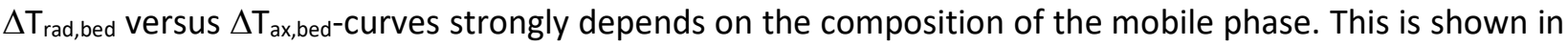


Fig. 9, where the mixture data already shown in Fig. 8 are compared to those obtained for pure water and pure ACN. This is done for both the natural convection (Fig. 9a) and the adiabatic thermal boundary condition (Fig. 9b). In both cases, there is a considerable increase of the slope of the $\Delta T_{\text {rad,bed }}$ versus $\Delta T_{\text {ax,bed }}{ }^{-}$ curves when going from the purely aqueous to the purely ACN mobile phase, with the 40/60 ACN/water mixture lying in between both extremes. The increase in slope with increasing ACN-fraction can be understood from the decrease in radial conductivity of the packed bed due to the much lower thermal conductivity of ACN compared to water. The increase in $\Delta T_{a x, b e d}$ is on the other hand related to the combined effect of the difference in mobile phase heat capacity, the amount of generated heat (proportional to flow rate and pressure drop) and heat lost to the environment. In the adiabatic case (Fig.

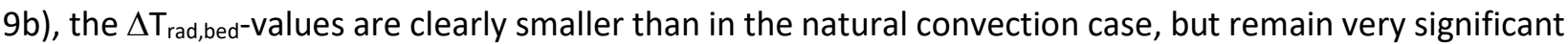
and display a similar relative dependency on the mobile phase composition. The data also show that developing solutions to create the perfect adiabatic environment for the column are not sufficient if nothing is changed to lower the backflow of heat along the metal column wall.

Please note that the change in mobile phase considered in Fig. 9 is made under the assumption the permeability of the bed at a given pressure is kept identical to that of the ACN/water-mixture. This implies the flow rates in the pure water and the pure $A C N$-case no longer correspond to $F=0.5 \mathrm{~mL} / \mathrm{min}$ but are changed inversely proportional with the change in viscosity, yielding a 1.56-2.28 times higher flow rate in the $\mathrm{ACN}$ case and a 1.06-1.17 times smaller flow rate in the $\mathrm{H}_{2} \mathrm{O}$ case (depending on the inlet pressure and thermal boundary conditions). The results obtained for the case where $F_{\text {in }}$ is kept constant for every considered liquid composition and every pressure is shown in the SM (Fig. S3). As can be noted the effects are qualitatively similar, but less outspoken as cases with the same inlet pressure now also represent a same amount of heat generated.

While the pressure coordinate in Figs 8 and 9 has been eliminated by directly plotting $\Delta T_{\text {rad,bed }}$ versus $\Delta \mathrm{T}_{\text {ax,bed, }}$, the corresponding plots of $\Delta \mathrm{T}_{\text {rad,bed }}$ versus $\Delta \mathrm{P}$ and $\Delta \mathrm{T}_{\text {ax,bed }}$ versus $\Delta \mathrm{P}$ are respectively shown in Figs. 10 and $\mathrm{S} 4$ of the Supplementary Material (SM). Fig. 10 shows $\Delta \mathrm{T}_{\text {rad,bed }}$ increases linearly with increasing $\Delta \mathrm{P}$ up to the highest considered $\Delta \mathrm{P}$ (Pearson's correlation coefficient $>0.999$ ), with the slope depending on the mobile phase composition and thermal boundary conditions.

The nearly linear relationship with $\Delta \mathrm{P}$ allows to conclude that moving to a 2500 bar operation would simply double the radial temperature gradient compared to working at a currently typical maximal pressure of 1250 bar. Fig. 9 shows that at 1250 bar $\Delta \mathrm{T}_{\text {rad,bed }}$ in a $2.1 \mathrm{~mm}$ column can be expected to be of the order of $0.75^{\circ} \mathrm{C}$ for pure water, some $1.5^{\circ} \mathrm{C}$ for the $\mathrm{ACN} /$ water mixture and some $2.5^{\circ} \mathrm{C}$ for pure $\mathrm{ACN}$. The loss in column efficiency these temperature differences are generating is something the chromatographic community has, out of necessity, learned to live with. Considering now that a doubling of the inlet pressure 
would double the radial temperature differences, it follows immediately that, in order to bring these differences back to the current level, a solution needs to be found that could halve the difference again.

\subsubsection{Bed conductivity enhancement solutions}

In this and below section, it is investigated what solutions could exist to halve the radial temperature gradients in a $2.1 \times 50 \mathrm{~mm}$ column operated at 2500 bar, or even reduce it below that level.

A solution already suggested in literature would consist of using particles with an enhanced thermal conductivity ${ }^{[24]}$. Grinias et al. showed experimentally that the presence of a "regular" solid silica core impacts the thermal behavior and efficiency of chromatographic columns ${ }^{[25]}$. To investigate this, Fig. 11

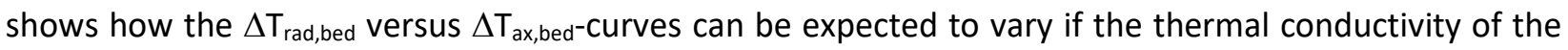
bed could be increased. Data are shown for the 40/60 ACN/water-mixture (Fig. 11a) as well as for pure ACN (Fig. 11b). The pure water case is not considered, as the radial thermal gradient problem is less stringent. The observed effect is furthermore very similar to that of the two other considered fluids.

The first important conclusion from Fig. 11 is that, within the investigated range of considered $k_{\text {eff- }}$ increases, the increase in $k_{\text {eff }}$ has nearly no effect on the axial temperature difference, while the radial temperature difference decreases following a nearly perfect inversely proportional relationship with keff:

$$
\Delta T_{\text {rad, bed }} \sim 1 / k_{\text {eff }}
$$

A second important conclusion is that roughly a doubling of $k_{\text {eff }}$ would be needed in order to bring the $\Delta \mathrm{T}_{\text {rad,bed }}$ at 2500 bar below its current value experienced at $1250 \mathrm{bar}$ (levels indicated by dashed horizontal lines). As can be noted from Fig. 6 , this is not possible with particulate beds (maximal enhancement=55\%), while such a doubling would be easily within reach if a monolithic bed structure consisting of a highly conductive core could be produced. As can be seen from Fig. 5, the thermal conductivity enhancement of monolithic structures can easily amount up to even a factor of 40 , due to the strong degree of axial connectivity of the monolithic structure.

\subsubsection{Other solutions}

Next to enhancing the radial heat transport, another way to suppress the creation of radial gradients, at least conceptually, would be to replace the highly conductive metal of the column wall with a less conductive material to stop the radial heat losses at the column inner wall instead of at its outer wall. Provided such a material possessing the required mechanical properties can be found, this would eliminate the aforementioned problem of the backflow of heat leading to the relatively large radial gradients under perfect adiabatic conditions observed in Fig. 8 and $9 b$.

The effect of the conductivity of the column tube wall is investigated in Fig. 12, where the natural convection and adiabatic case data for the $40 / 60 \mathrm{ACN} / \mathrm{H}_{2} \mathrm{O}$ mixture obtained in a metal tubing column 
already shown in Fig. 11a (solid red line in Fig. 12) are compared with the temperature gradient values one can expect when the entire column (wall + endfitting pieces) would be made in a material that is approximately 4, 16, 64 and 256 times less conductive than what is typical for stainless steel.

In agreement with one's physical expectations, making the column wall less conductive indeed leads to a reduction of the radial temperature gradient. Since in steady-state, the produced heat needs to leave the column anyhow, the reduction of the radial gradient is inevitably also accompanied by an increase of the axial temperature gradient. From a practical point of view, the most interesting data set is the one for $\mathrm{k}_{\text {wall }}=0.25 \mathrm{~W} / \mathrm{m} . \mathrm{K}$ as this is representative of a column that would consist entirely of PEEK. As can be noted, such a column would suffer much less from radial temperature differences than a metal column $\left(\Delta \mathrm{T}_{\text {rad,bed }}=0.66^{\circ} \mathrm{C}\right.$ instead of $2.13^{\circ} \mathrm{C}$ for a stainless steel wall column operated at 2500 bar under natural convection conditions). For the case of a 4-fold wall conductivity reduction (certain metal oxides such as $\mathrm{Al}$ and $\mathrm{Zr}$-oxide or rock like materials such as quartz, marble and granite have thermal conductivities in this range), the effect on $\Delta T_{\text {rad,bed }}$ is still limited. It is only if a material with a 16 -fold reduction ( $k_{\text {wall }}=1 \mathrm{~W} / \mathrm{m} . \mathrm{K}$, representative of traditional low thermal conductivity ceramic materials ${ }^{[26]}$ ) is being used that $\Delta T_{\text {rad,bed }}$ could be brought under $1^{\circ} \mathrm{C}$ (in case of natural convection).

Whereas increasing the thermal conductivity of the bed has barely any effect on the axial temperature gradient $\left(\Delta T_{\text {ax,bed}}\right.$, see Fig. 11$)$, the use of low-conductivity column walls clearly leads to a significant increase of the axial temperature increase. This is clearly a drawback of this approach.

The adiabatic-case data in Fig. 12b display a similar pattern, albeit the use of the lower conductivity materials now really drives $\Delta T_{\text {rad,bed }}$ to values $<0.1 \mathrm{~K}$, showing that if a change to a less conductive column wall material could be combined with a perfect adiabatic operation (as would obtained when surrounding the columns with a vacuum jacket as proposed by Gritti ${ }^{[27]}$ ), the radial temperature gradients would be reduced to a level where its effect on column band broadening would be truly insignificant. The increase of the axial temperature gradient is however more pronounced than in the natural convection case shown in Fig. 12a.

Since an integral PEEK column cannot be expected to withstand high internal pressures without deformation, except when conceiving impractically thick column walls, we also found it instructive to investigate whether it would suffice to coat only the inner wall of a metal tube with a thin $(100 \mu \mathrm{m})$ PEEK layer (keeping the column ID constant), using the PEEK layer for thermal insulation and the surrounding metal tube for mechanical strength. As can be noted from the position of point A in Fig. 12, the effect of the thin PEEK layer is relatively small and only lowers $\Delta T_{\text {rad,bed }}$ with some $17 \%$ (compared to the $69 \%$ decrease of an integral PEEK column. This is due to the fact that the heat transfer resistance of the thin layer is insufficient to block a sufficient part of the radial heat transfer, such that there remains a significant 
backflow of heat along the metal part of the wall. In an integral PEEK column, not only the radial heat transfer is blocked to a much more significant extent (column wall is about 20 times thicker than $100 \mu \mathrm{m}$ PEEK layer roughly leading to a 12 times larger thermal resistance), but also the axial back flow of heat is suppressed to a much larger extent (conductivity of PEEK is about 64 times less than that of stainless steel). As can be noted from interpolating between points $C$ and $D$, a $100 \mu \mathrm{m}$ thin insulating layer would need to be made of a material that is 36 times less conductive than PEEK (and hence 2324 times less conductive than stainless steel) to obtain the same degree of radial temperature gradient reduction one could obtain if it would be possible to use an integral PEEK column.

Finally, comparing the black curve data ( $1 \mathrm{~mm}$ column) with the other data ( $2.1 \mathrm{~mm}$ columns) in Fig. 12 shows that the most simple and straightforward approach to abating the viscous heating band broadening still consists of resorting to thinner columns. Obviously, the field is not ready for this yet, given the ongoing debate about the feasibility to pack high quality $1 \mathrm{~mm}$ columns ${ }^{[28,29]}$, as well as the requirement to move to a micro-flow instrument in order to use these columns without extra-column band broadening losses.

\section{Conclusions}

Whereas the production of spherical core-shell particles with a high conductivity core can only be expected to produce a relatively moderate increase in the bed conductivity, the simulation with the core-shell monolithic structure conducted in the present study shows that the only way to use high conductivity solid cores to effectively abate the viscous heating problem in UHPLC at pressures above 2000 bar is by using structures where this solid core forms one uninterrupted path throughout the entire bed, as is the case in the presently considered idealized tetrahedral skeleton model structure. Whether or not it will ever be possible to produce such structures having the required small domain size (order $\mu \mathrm{m}$ ) is however an open question. Simulations conducted at the column level showed that the bed conductivities of such structures can be high enough to alleviate the radial temperature gradients in the bed and offer a solution to the viscous heating problem, while the bed conductivities attained by using spherical core-shell particles with a high conductivity core were too low. An alternative approach, being the use of low conductivity wall materials, was investigated. It was shown that this approach also led to reduced radial temperature gradients. Besides practical considerations (e.g. mechanical strength), another downside of this approach was that the lower $\Delta \mathrm{T}_{\text {rad }}$ was inevitably accompanied by an increase in $\Delta \mathrm{T}_{\mathrm{ax}}$. This is disadvantageous, because it induces an extra loss in retention and unpredictable selectivity amongst other effects ${ }^{[30,31]}$. As predicted by theory, the most simple and straightforward solution to abate viscous heating obviously is a reduction of the column ID, as shown by the $1 \mathrm{~mm}$ ID simulations conducted at the end of this study. This solution however still requires the development of column packing procedures that work as well as for $2.1 \mathrm{~mm}$ ID columns ${ }^{[28]}$ and a new generation of instruments with further reduced extra-column volumes and dispersion sources as well as with an increased pressure rating. 


\section{Acknowledgements}

S. Deridder gratefully acknowledges a research grant from the Research Foundation - Flanders (FWOVlaanderen).

G. Desmet and W. Smits gratefully acknowledge the support of ERC Advanced Grant nr. 695067.

\section{References}

[1] H.-J. Lin, S. Horvath, Viscous dissipation in packed beds, Chem. Eng. Sci. 36 (1981) 47-55. DOI: 10.1016/0009-2509(81)80047-4

[2] H. Poppe, J.C. Kraak, J.F.K. Huber, J.H.M. van den Berg, Temperature-gradients in HPLC Columns due to Viscous Heat Dissipation, Chromatographia 14 (1981) 515-523.

DOI: $10.1007 / \mathrm{bf02265631}$

[3] H. Poppe, J.C. Kraak, Influence of thermal conditions on the efficiency of high-performance liquid chromatographic columns, J. Chromatogr. 282 (1983) 399-412.

DOI: 10.1016/S0021-9673(00)91617-0

[4] U. Neue, M. Kele, Performance of idealized column structures under high pressure, J. Chromatogr. A 1149 (2007) 236-244.

DOI: $10.1016 /$ j.chroma.2007.03.042

[5] F. Gritti, M. Martin, G. Guiochon, Influence of viscous friction heating on the efficiency of columns operated under very high pressures, Anal. Chem. 81 (2009) 3365-3384.

DOI: $10.1021 / a c 802632 x$

[6] K. Kaczmarski, F. Gritti, J. Kostka, G. Guiochon, Modeling of thermal processes in high pressure liquid chromatography: II. Thermal heterogeneity at very high pressures, J. Chromatogr. A 1216 (2009) 6575-6586.

DOI: 10.1016/j.chroma.2009.07.049

[7] K. Broeckhoven, G. Desmet, Considerations for the use of ultra-high pressures in liquid chromatography for 2.1 mm inner diameter columns, J. Chromatogr. A 1523 (2017) 183-192. DOI: 10.1016/j.chroma.2017.07.040

[8] L. Tolley, J.W. Jorgenson, M.A. Moseley, Very High Pressure Gradient LC/MS/MS, Anal. Chem. 73 (2001) 2985-2991.

DOI: $10.1021 / a c 0010835$

[9] R.E. Majors, Current Trends in HPLC Column Usage, LC GC Eur. 25 (2012) 31-39.

DOI:/ 
S. Deridder, W. Smits, H. Benkahla, K. Broeckhoven, G. Desmet, Numerical and analytical investigation of the possibilities to enhance the thermal conductivity of core-shell particle packed beds, J. Chromatogr. A 1575 (2019) 26-33.

DOI: $10.1016 /$ j.chroma.2018.08.056

N. Vervoort, P. Gzil, G.V. Baron, G. Desmet, A correlation for the pressure drop in monolithic silica columns, Anal. Chem. 75 (2003) 843-850.

DOI: $10.1021 /$ ac0262199

Y.A. Çengel, Heat transfer: a practical approach, 2nd ed., McGraw-Hill, New York, 2003.

S. W. Churchill, H. H. S. Chu, Correlating equations for laminar and turbulent free convection from a horizontal cylinder, Int. J. Heat Mass Tran. 18 (1975) 1049-1053.

DOI: 10.1016/0017-9310(75)90222-7

J. Billen, K. Broeckhoven, A. Liekens, K. Choiket, G. Rozing, G. Desmet, Influence of pressure and temperature on the physico-chemical properties of mobile phase mixtures commonly used in highperformance liquid chromatography, J. Chromatogr. A 1210 (2008) 30-44.

DOI: 10.1016/j.chroma.2008.09.056

R.J. Hulse, M.W. Anderson, M.D. Bybee, D.D. Gonda, C.A. Miller,J.L. Oscarson, R.L. Rowley, W.V. Wilding, Liquid Thermal Conductivities of Acetonitrile, Diethyl Sulfide, Hexamethyleneimine, Tetrahydrothiophene and Tetramethylethylenediamine, J. Chem. Eng. Data 49 (2004) 1433-1435. DOI: $10.1021 /$ je0498661

A.M. Kolker, L.P. Safonova, Molar heat capacities of the (water + acetonitrile) mixtures at $\mathrm{T}=(283.15$, 298.15, 313.15, and 328.15) K, J. Chem. Thermodyn. 42 (2010) 1209-1212.

DOI: $10.1016 /$ j.jct.2010.04.019

D.T. Jamieson, J. B. Irving, J. S. Tudhope, Liquid Thermal Conductivity. A Data Survey to 1973, H. M. Stationary Office, Edinburgh, 1975.

M. Martin, G. Guiochon, Effects of high pressure in liquid chromatography, J. Chromatogr. A 1090 (2005) 16-38.

DOI: 10.1016/j.chroma.2005.06.005

F. Gritti, G. Guiochon, Complete temperature profiles in ultra-high-pressure liquid chromatography columns, Anal. Chem. 80 (2008) 5009-5020.

DOI: $10.1021 /$ ac800280c

D. Cabooter, K. Broeckhoven, R. Sterken, A. Vanmessen, I. Vandendael, K. Nakanishi, S. Deridder, G. Desmet, Detailed characterization of the kinetic performance of first and second generation silica monolithic columns for reversed-phase chromatography separations, J. Chromatogr. A 1325 (2014) 72-82. 
DOI: 10.1016/j.chroma.2013.11.047

[21] D. Åsberg, M. Chutkowski, M. Lesko, J. Samuelsson, K. Kaczmarski, T. Fornstedt, A practical approach for predicting retention time shifts due to pressure and temperature gradients in ultra-highpressure liquid chromatography, J. Chromatography A 1479 (2017) 107-120.

DOI: 10.1016/j.chroma.2016.11.050

K. Kaczmarski, J. Kostka, W. Zapała, G. Guiochon, Modeling of thermal processes in high pressure liquid chromatography I. Low pressure onset of thermal heterogeneity, J. Chromatogr. A 1216 (2009) 6560-6574.

DOI: 10.1016/j.chroma.2009.07.020

[23] K. Kaczmarski, F. Gritti, G. Guiochon, Prediction of the influence of the heat generated by viscous friction on the efficiency of chromatography columns, J. Chromatogr. A 1177 (2008) 92-104. DOI: 10.1016/j.chroma.2007.11.009

[24] F. Gritti, G. Guiochon, The current revolution in column technology: How it began, where is it going?, J. Chromtogr. A 1228 (2012) 2-19.

DOI: 10.1016/j.chroma.2011.07.014

[25] J. P. Grinias, D. S. Keil, J. W. Jorgenson, Observation of enhanced heat dissipation in columns packed with superficially porous particles, J. Chromtogr. A 1371 (2014) 261-264.

DOI: 10.1016/j.chroma.2014.10.075

[26] J. García Ten, M.J. Orts, A. Saburit, G. Silva, Thermal conductivity of traditional ceramics. Part I: Influence of bulk density and firing temperature, Ceram. Int. 36 (2010) 1951-1959.

DOI: 10.1016/j.ceramint.2010.05.012

[27] F. Gritti, Vacuum-Jacketed Columns: Maximum Efficiency, Easy Deployment Without Oven, and Improved LC-MS Performance, LC GC Eur. 32 (2019) 8-13.

DOI:/

F. Gritti, M.F. Wahab, Understanding the Science Behind Packing High-Efficiency Columns and Capillaries: Facts, Fundamentals, Challenges, and Future Directions, LC GC Eur. 31 (2018) 90-101. DOI:/

[29] J.A. Anspach, T.D. Maloney, L.A. Colón, Ultrahigh-pressure liquid chromatography using a 1-mm id column packed with 1.5- $\mu$ m porous particles, J. Sep. Sci. 30 (2007) 1207-1213.

DOI: $10.1002 /$ jssc. 200600535

[30] K. Horváth, S. Horváth, D. Lukács, Effect of axial temperature gradient on chromatographic efficiency under adiabatic conditions, J. Chromatogr. A 1483 (2017) 80-85.

DOI: 10.1016/j.chroma.2016.12.063 
[31] S. Fekete, D. Guillarme, Estimation of pressure-, temperature- and frictional heating-related effects on proteins' retention under ultra-high-pressure liquid chromatographic conditions, J. Chromatogr. A 1393 (2015) 73-80.

DOI: 10.1016/j.chroma.2015.03.023 
Fig. 1:
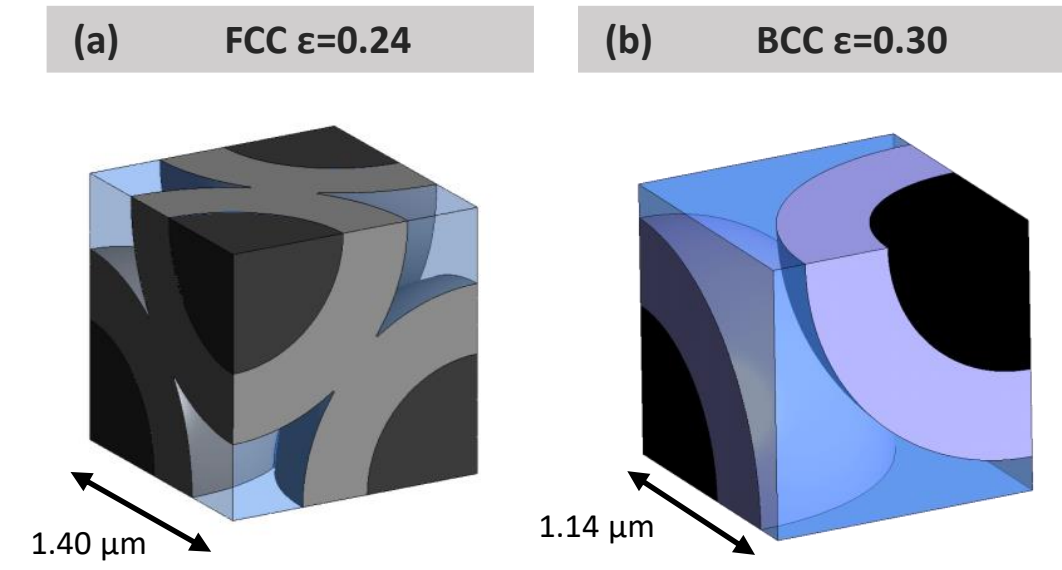

(c) $\mathrm{SC} \varepsilon=0.46$

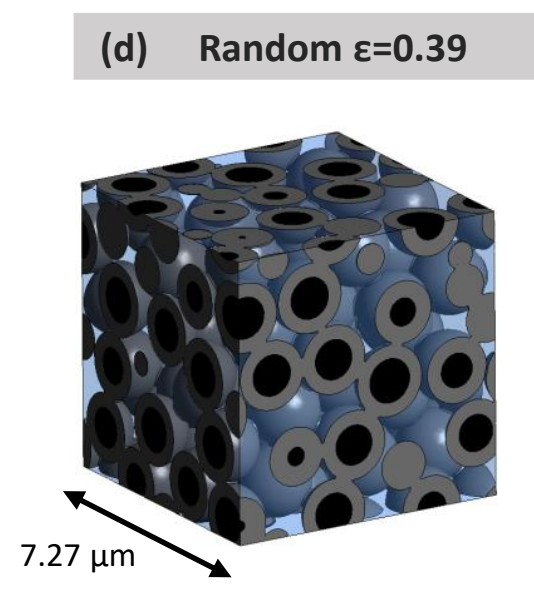

(e) $\operatorname{TSM} \varepsilon=0.39$
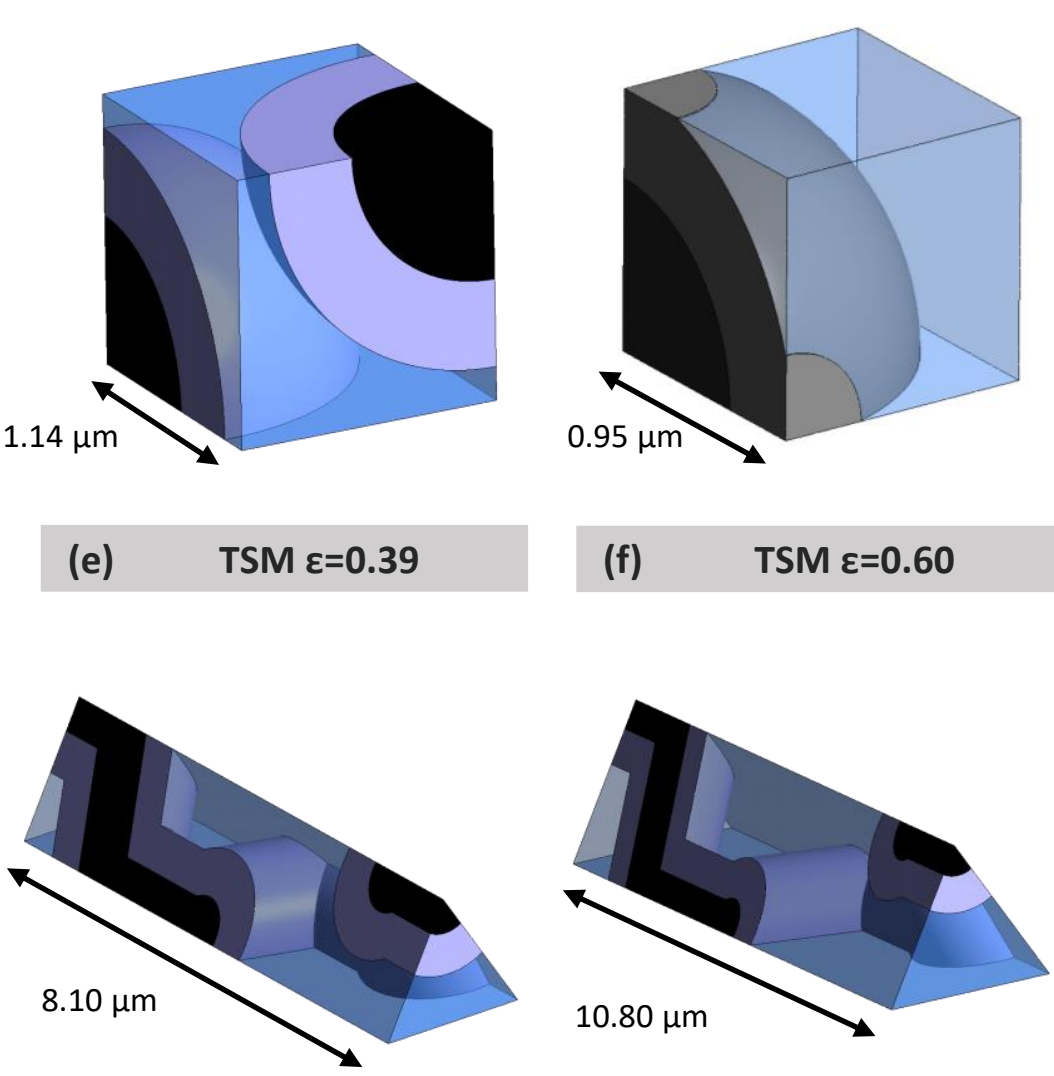
Fig. 2:

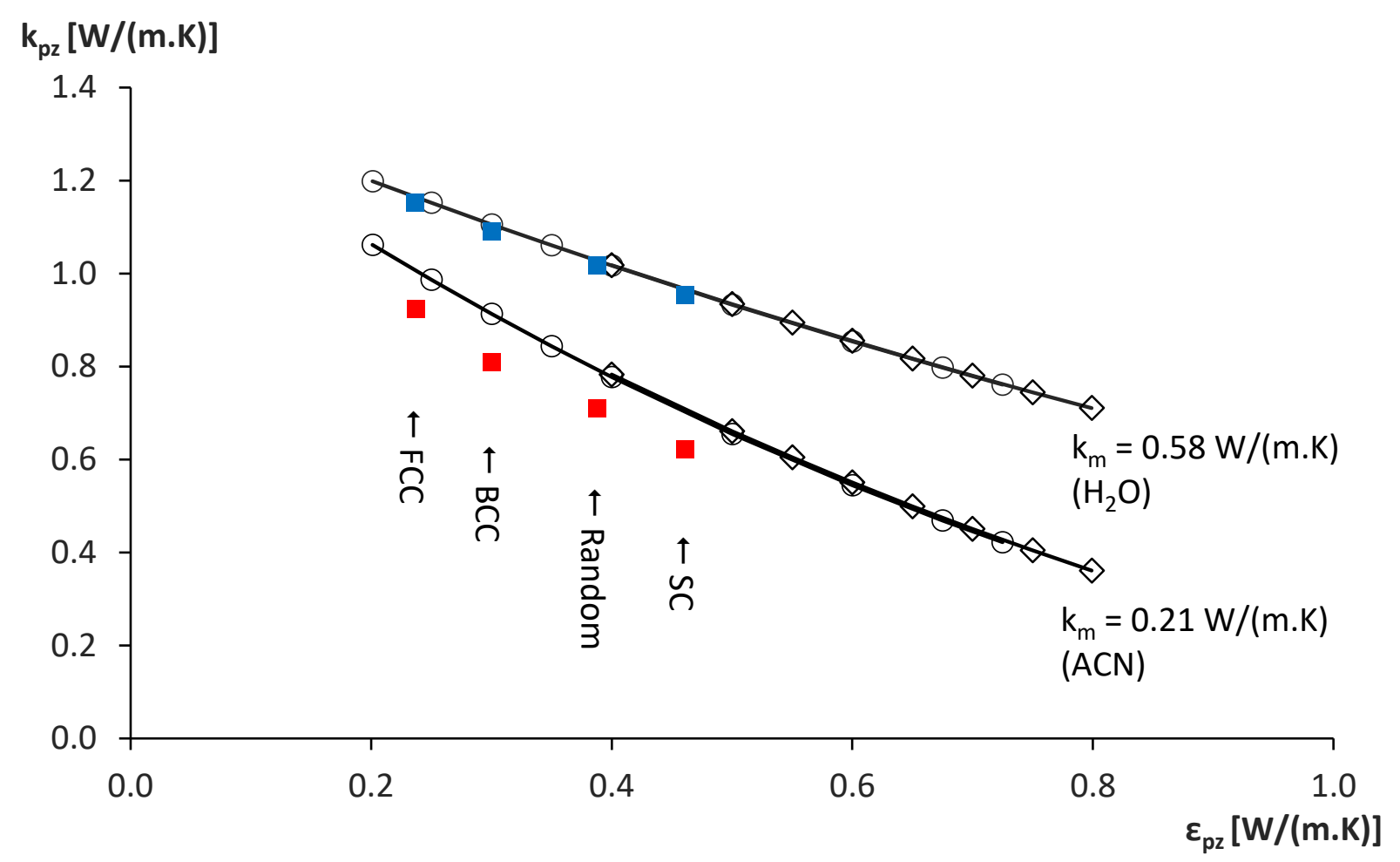


Fig. 3:

$$
\mathbf{k}_{\text {eff }} / \mathbf{k}_{\text {eff,u=0 }}[/] \quad \text { Random } \varepsilon_{\mathrm{e}}=0.39
$$

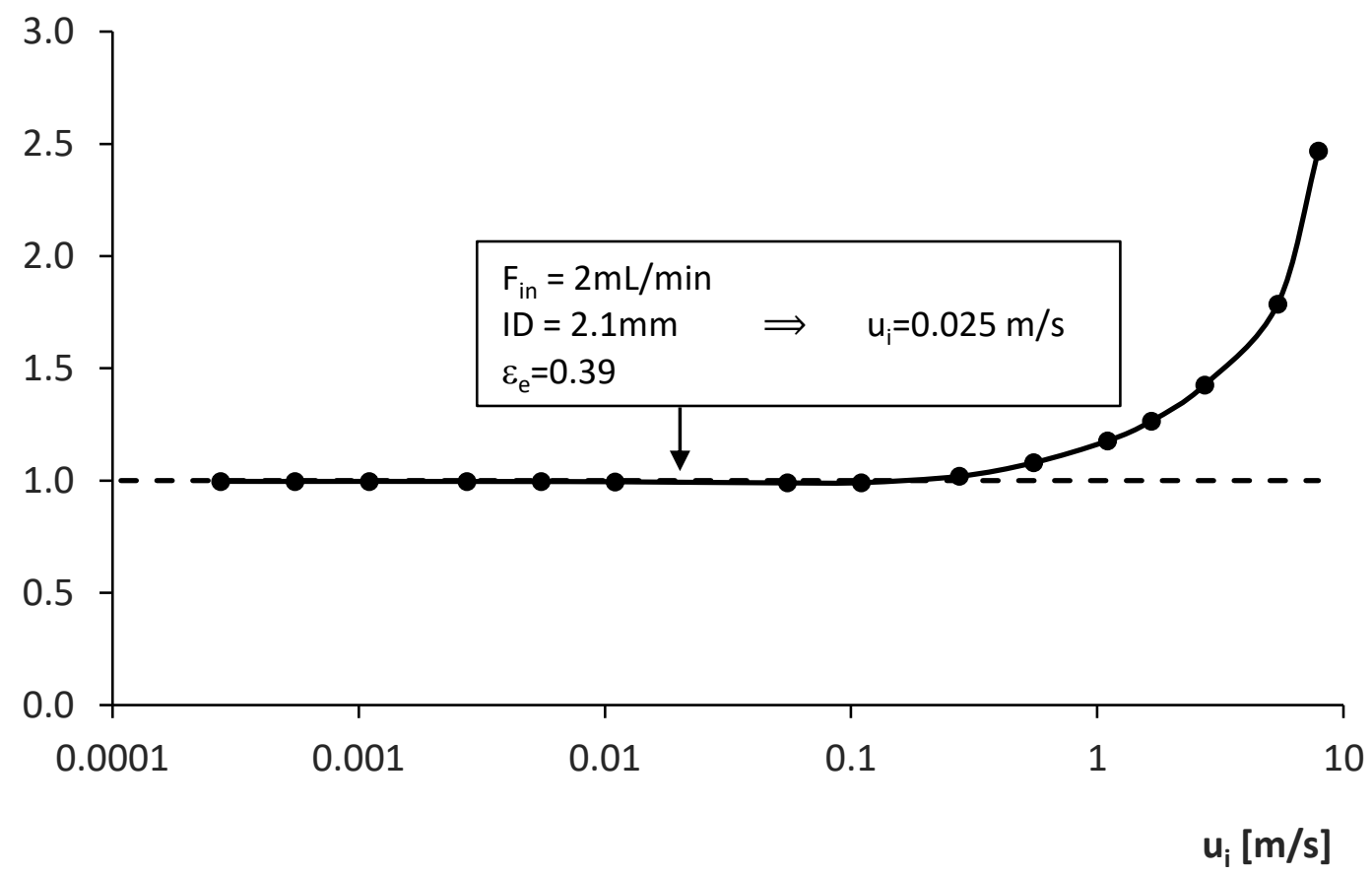


Fig. 4:

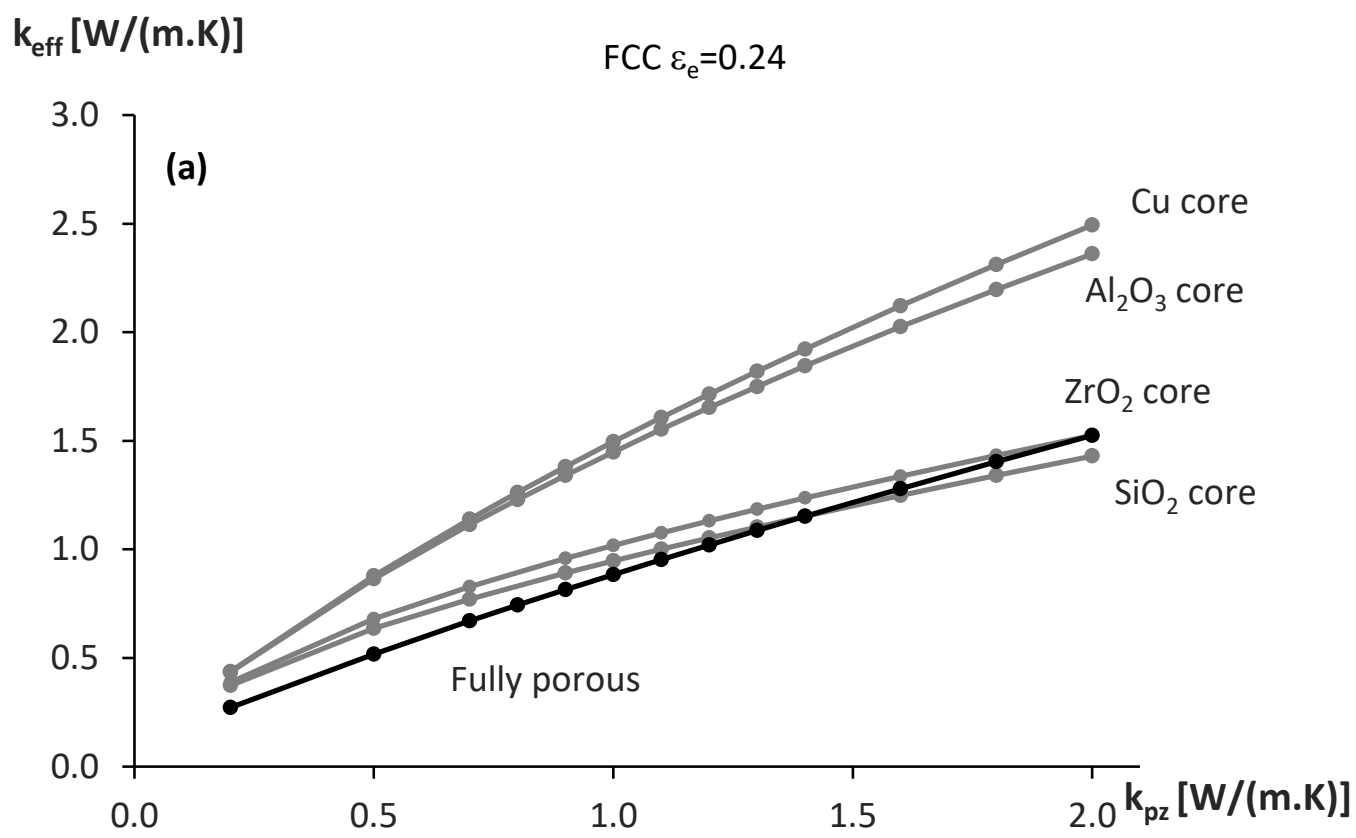

$k_{\text {eff }}[W /(m . K)]$

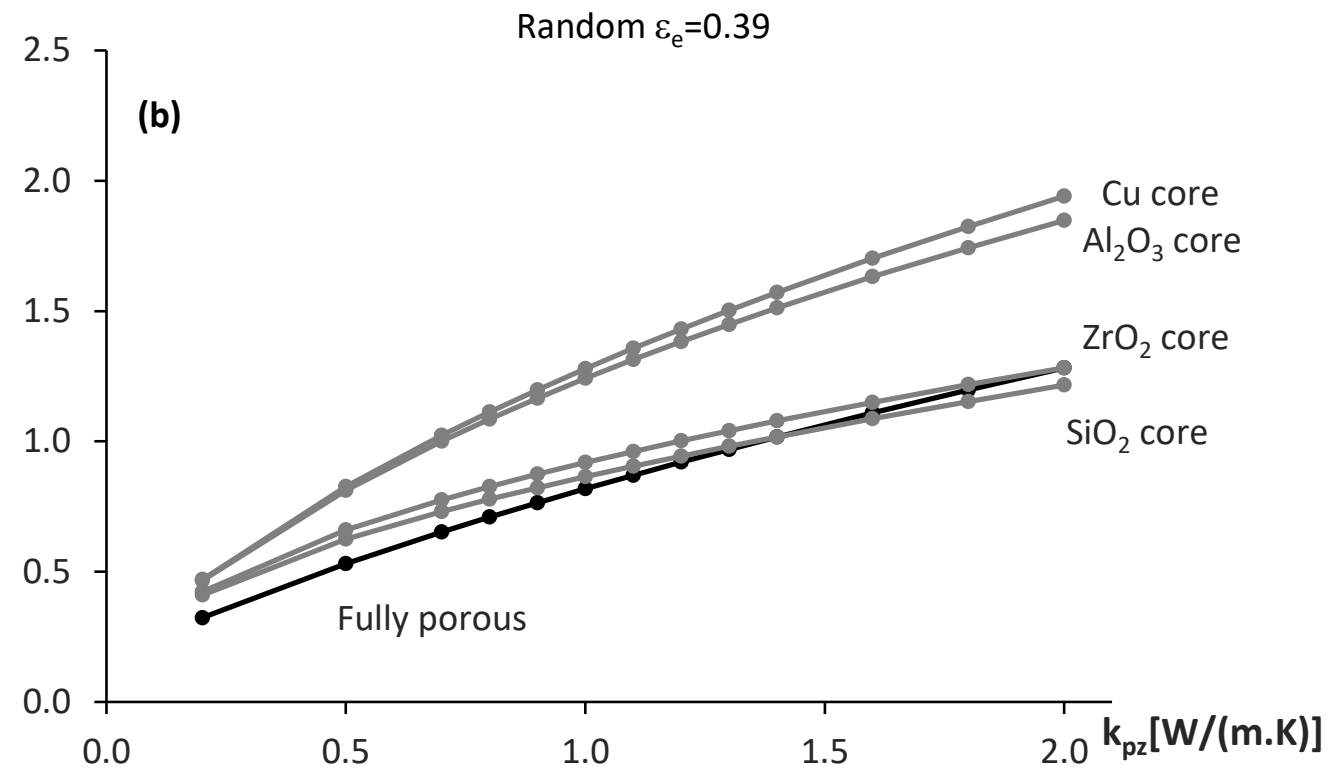


Fig. 5:

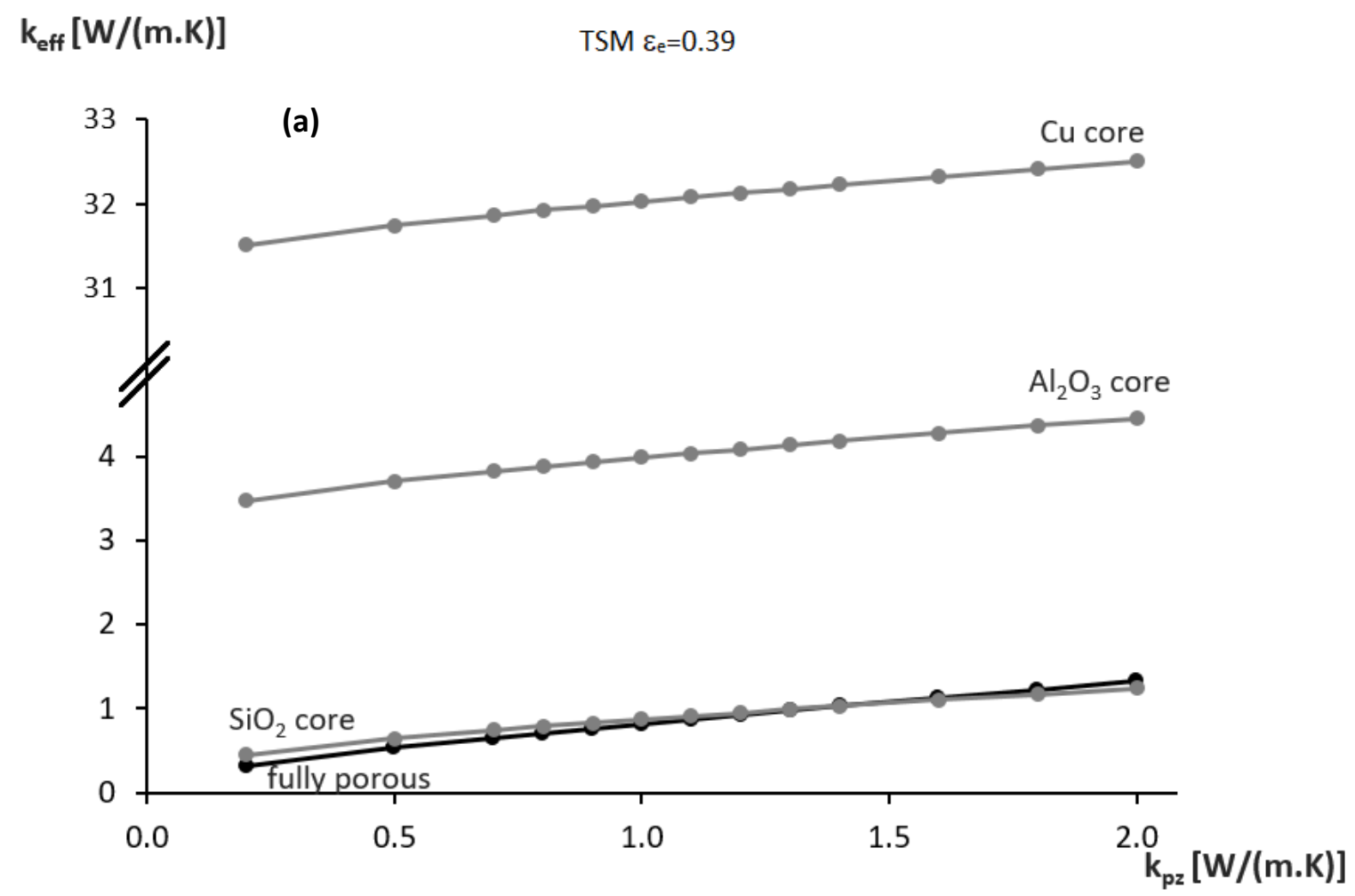

$k_{\text {eff }}[W /(m . K)]$

TSM $\varepsilon_{\mathrm{e}}=0.60$

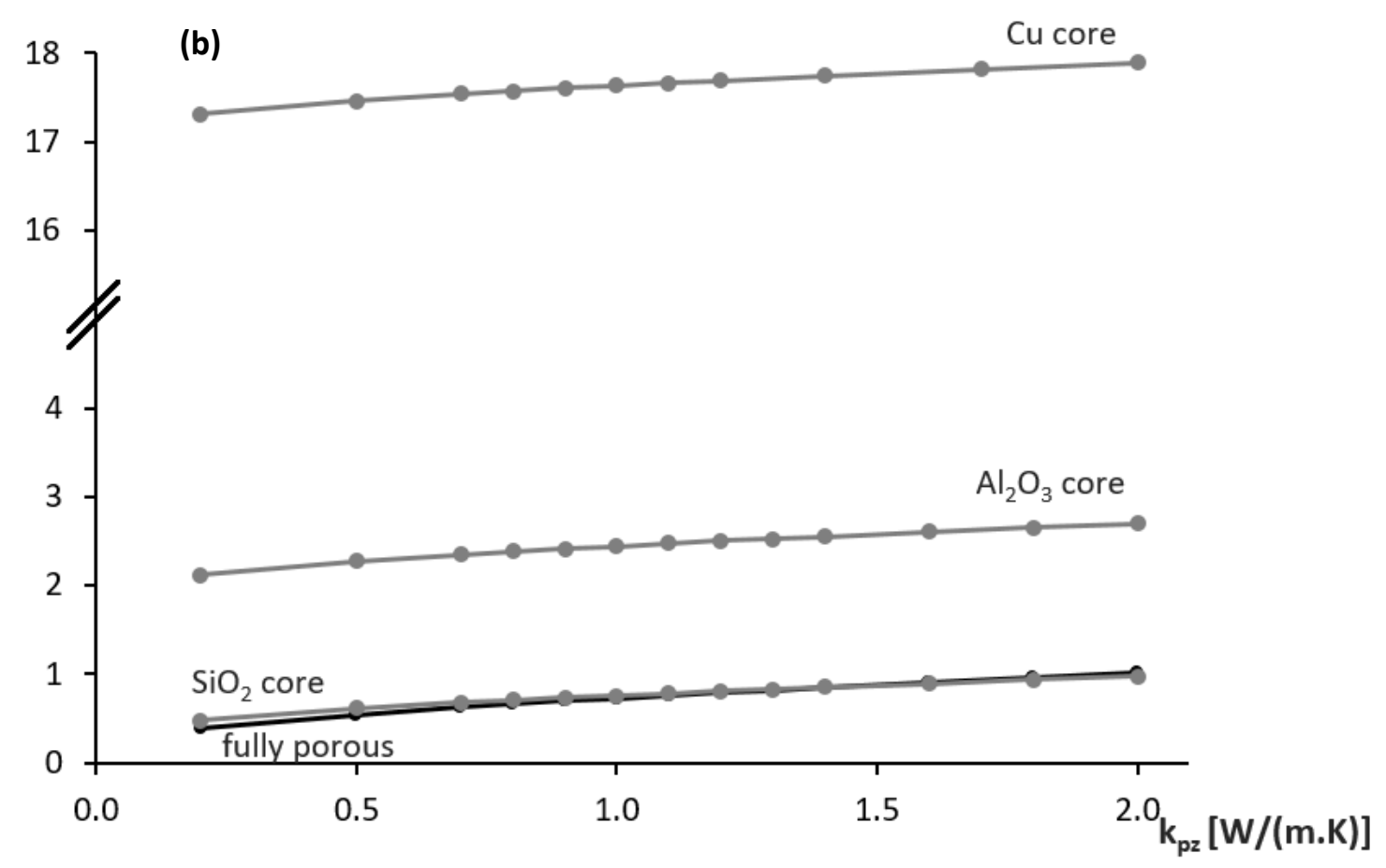


Fig. 6:

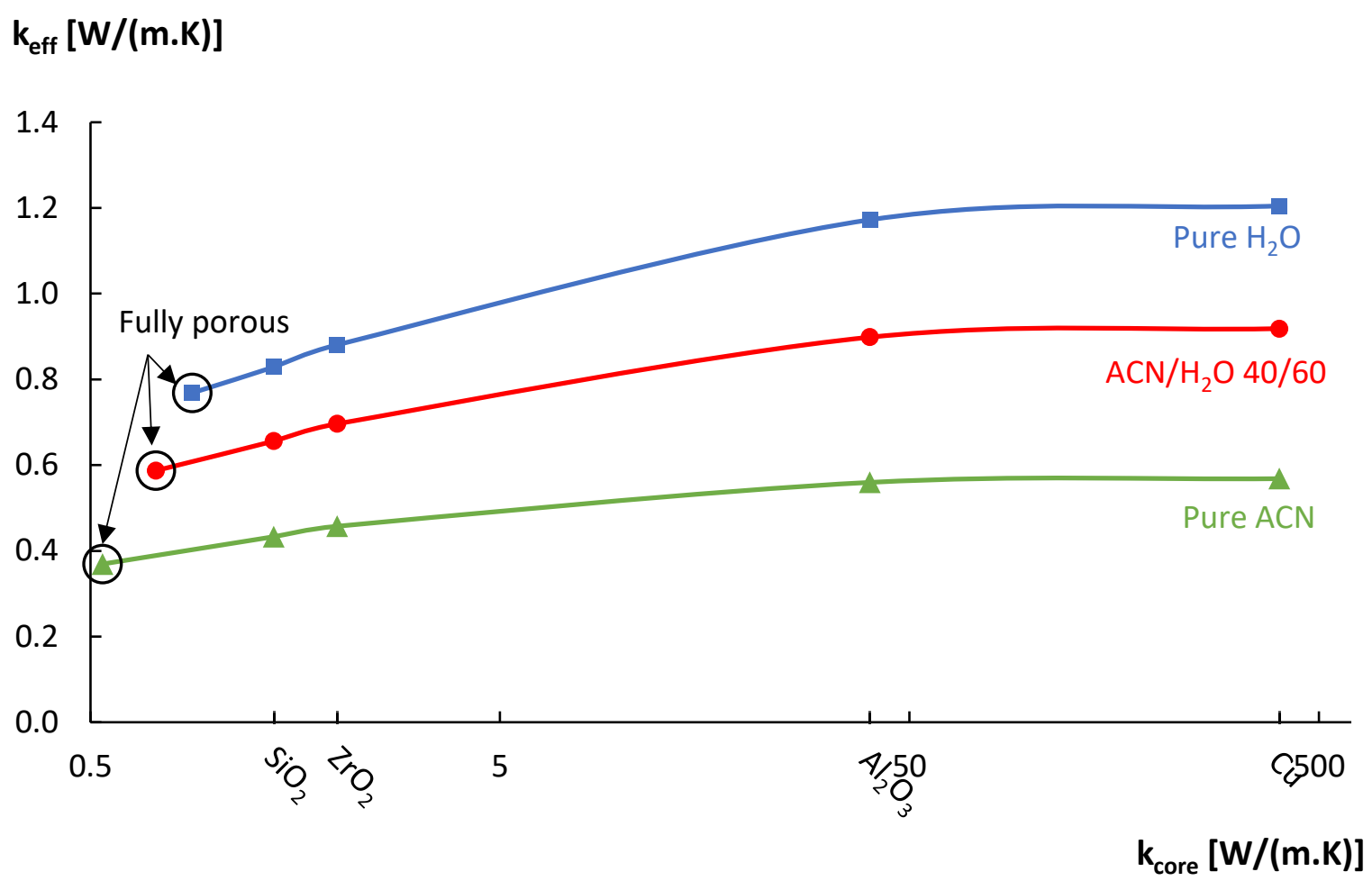


Fig. 7:
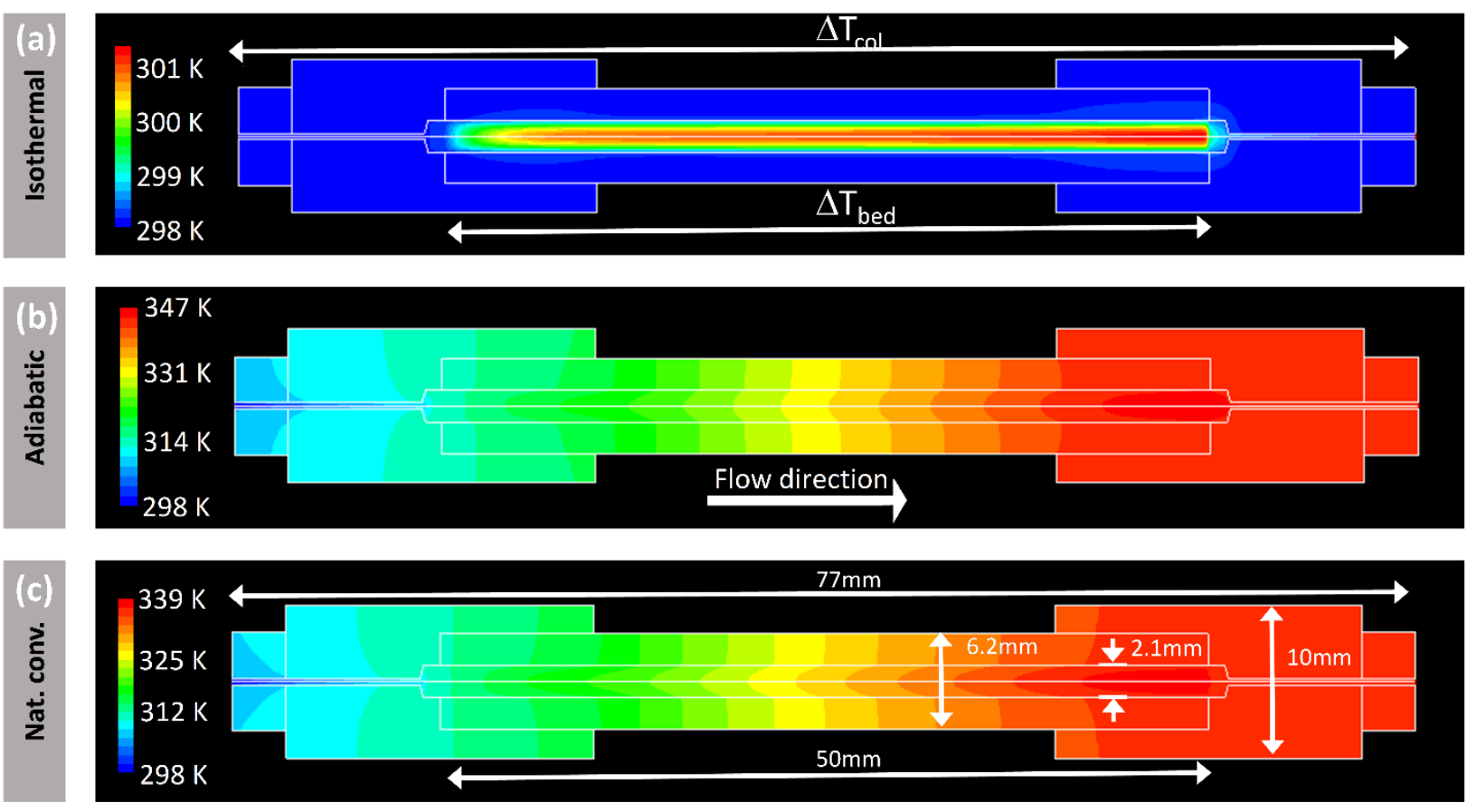
Fig. 8:
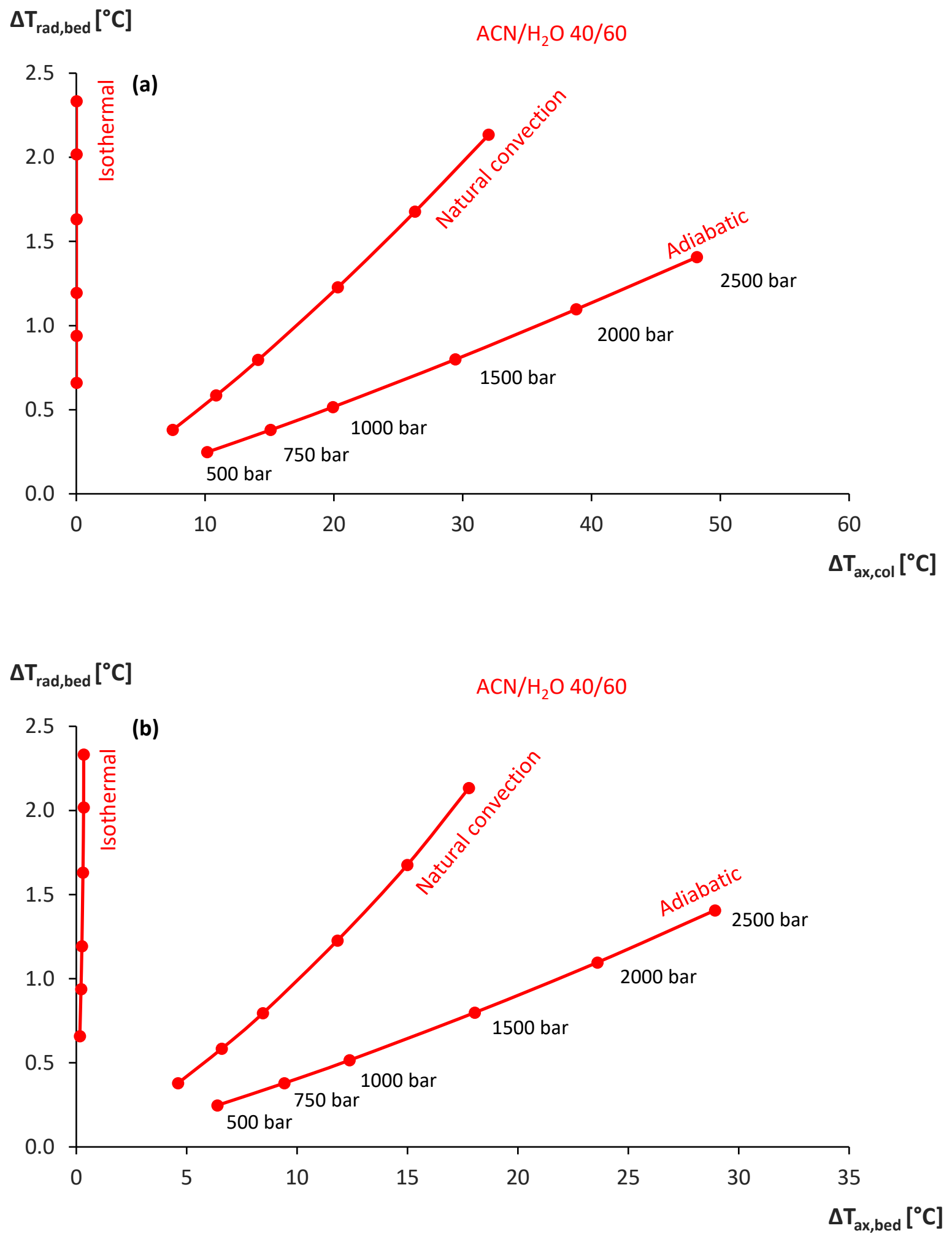
Fig. 9:

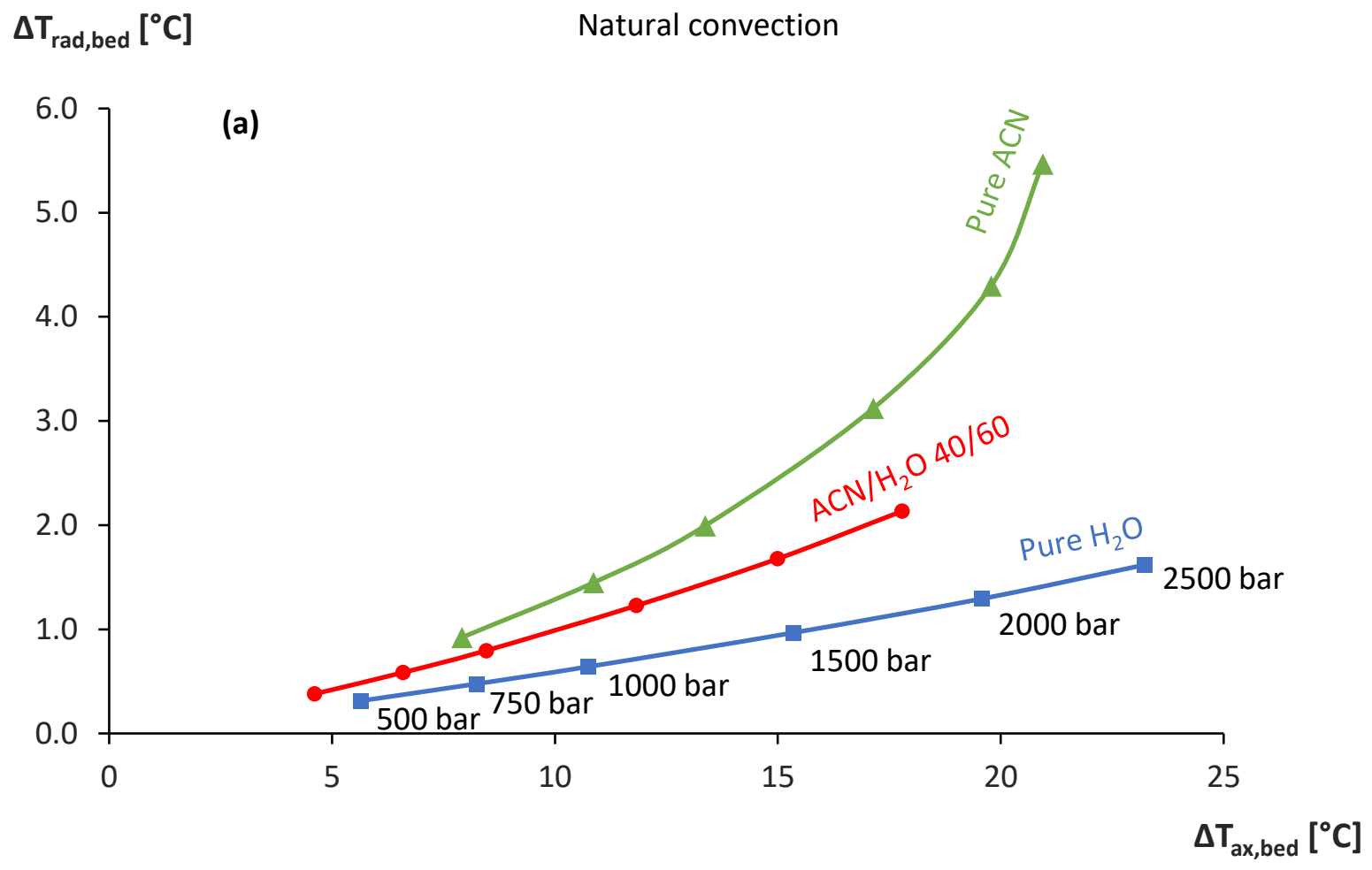

$\Delta \mathrm{T}_{\text {rad,bed }}\left[{ }^{\circ} \mathrm{C}\right]$

Adiabatic

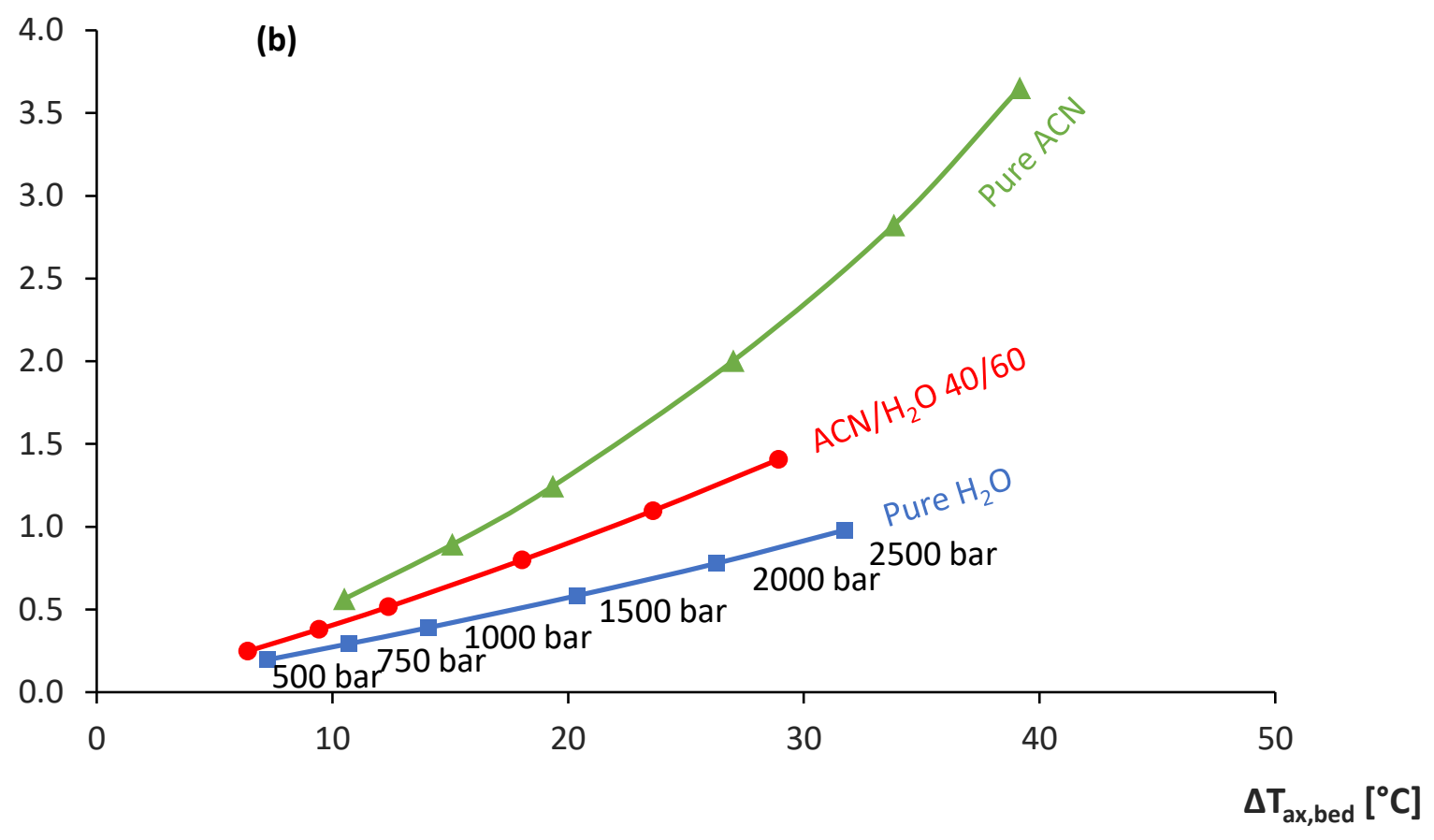


Fig. 10:

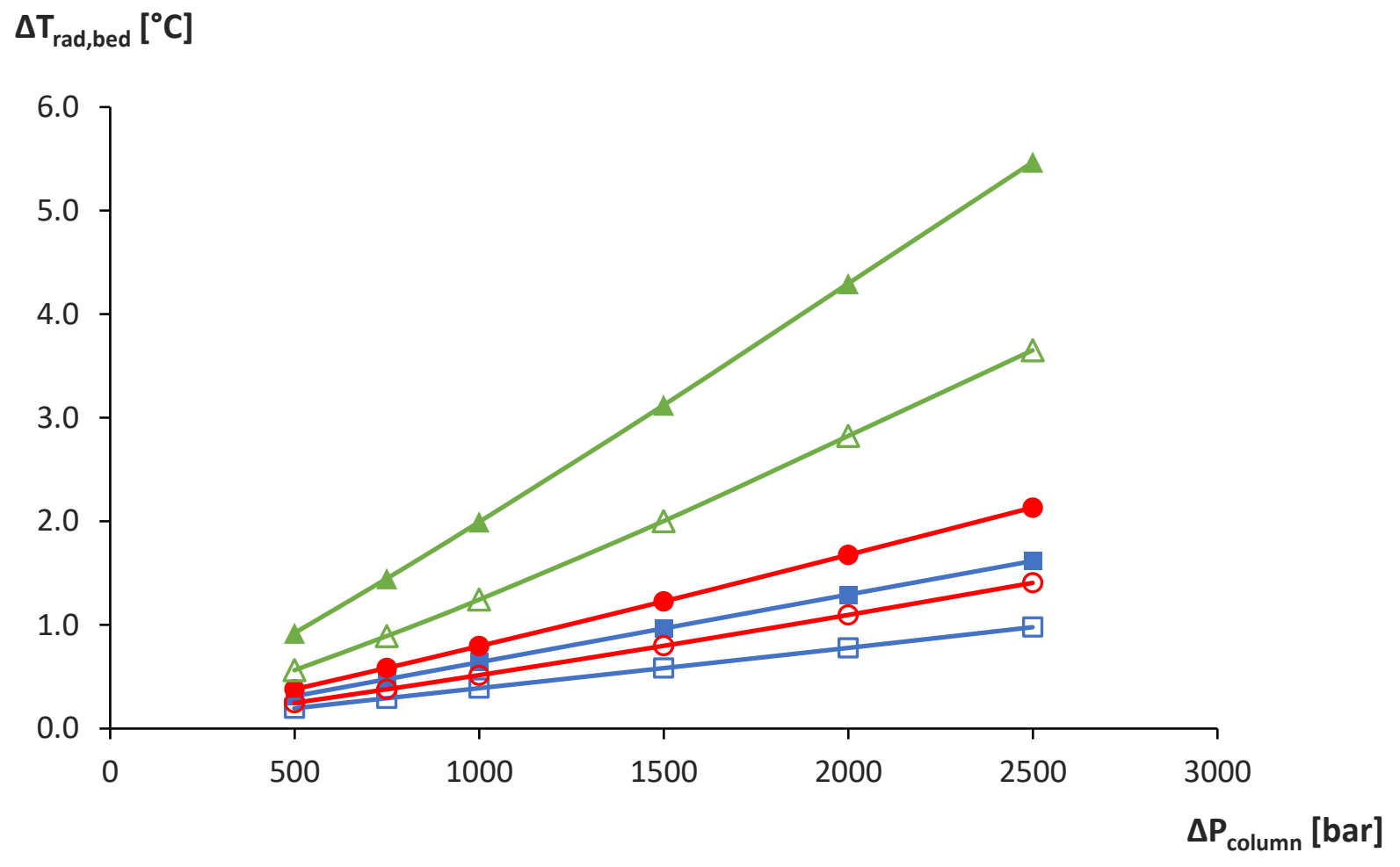


Fig. 11:

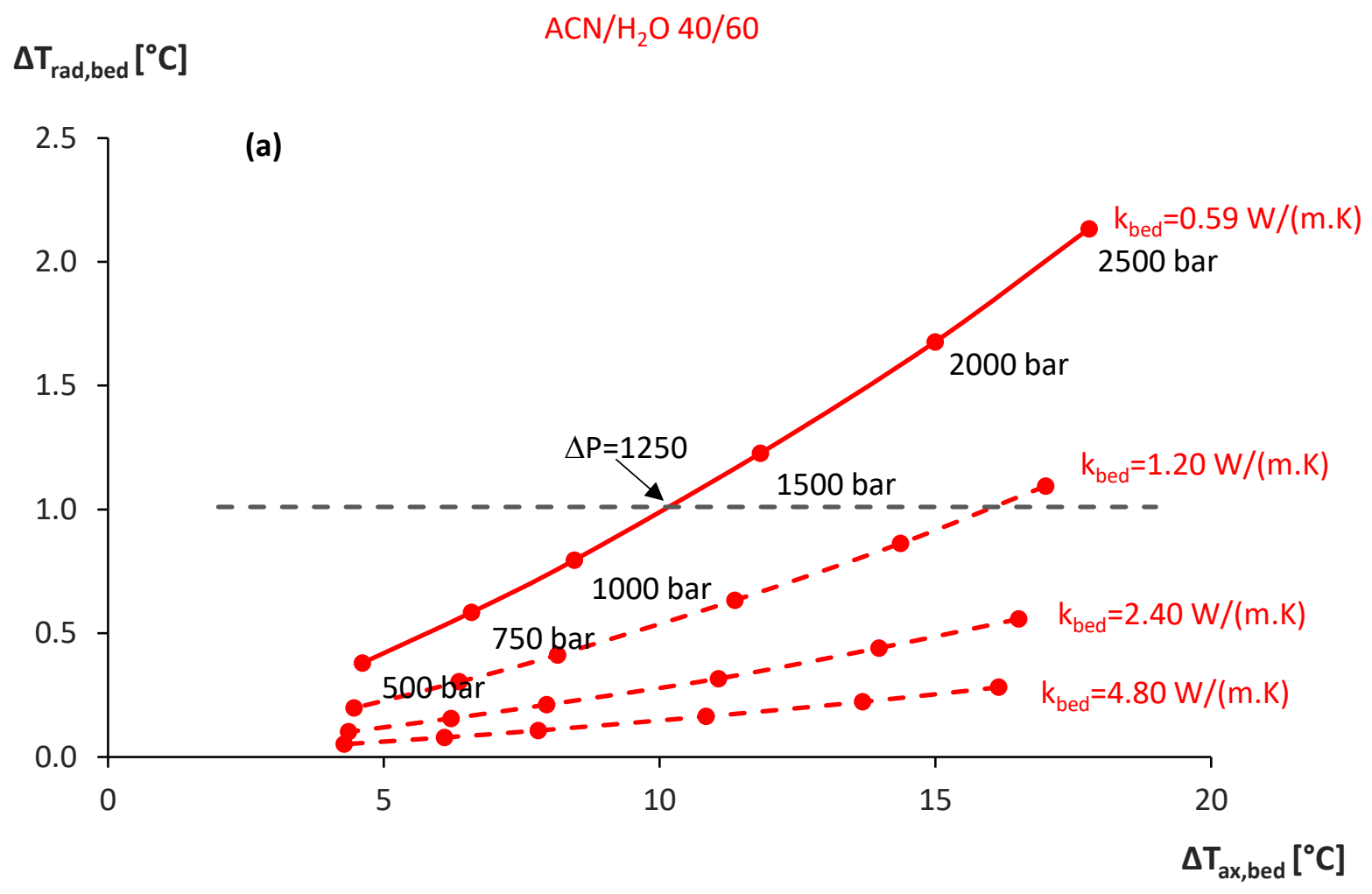

$\Delta \mathrm{T}_{\text {rad,bed }}\left[{ }^{\circ} \mathrm{C}\right]$

Pure ACN

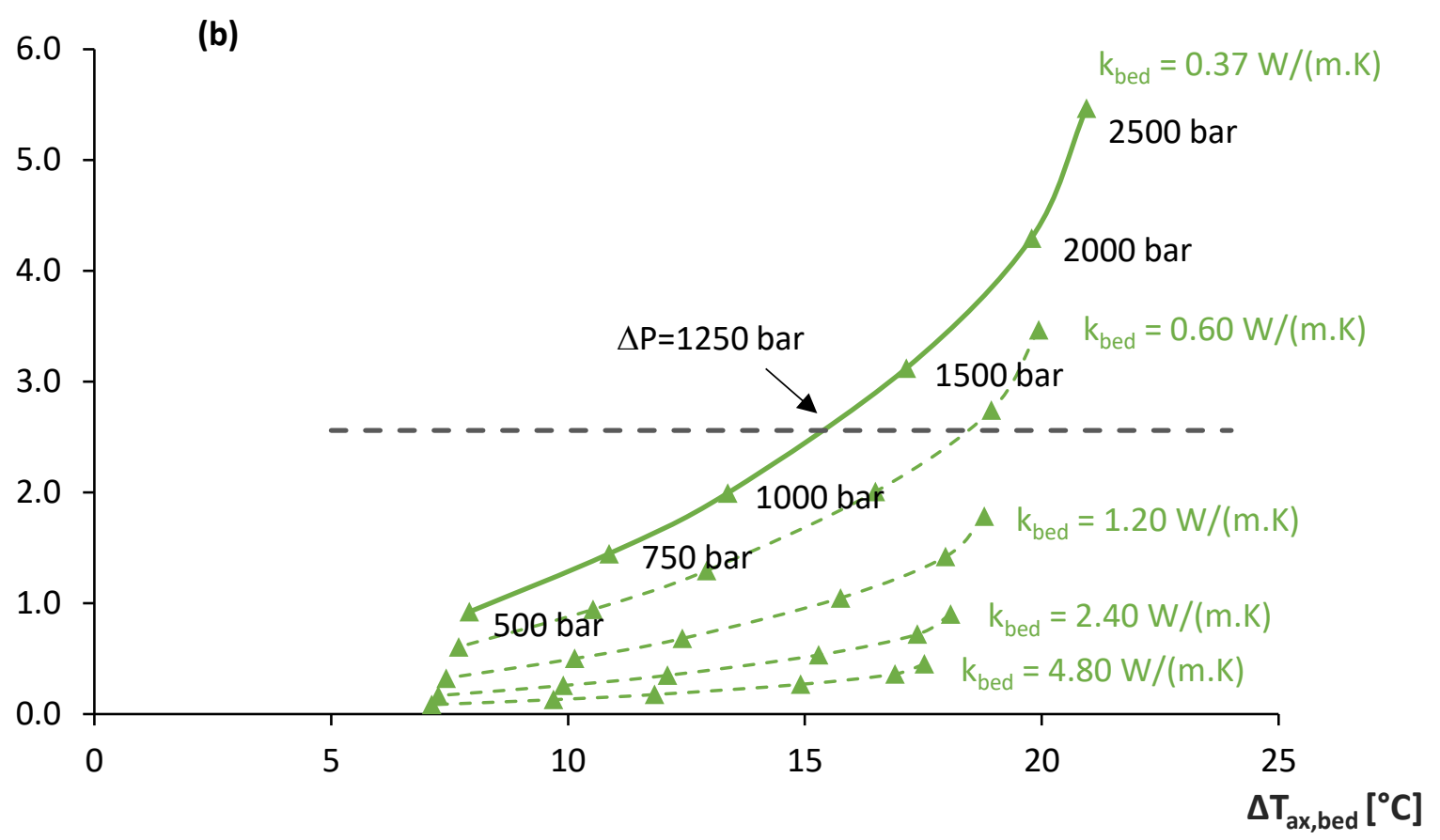


Fig. 12:

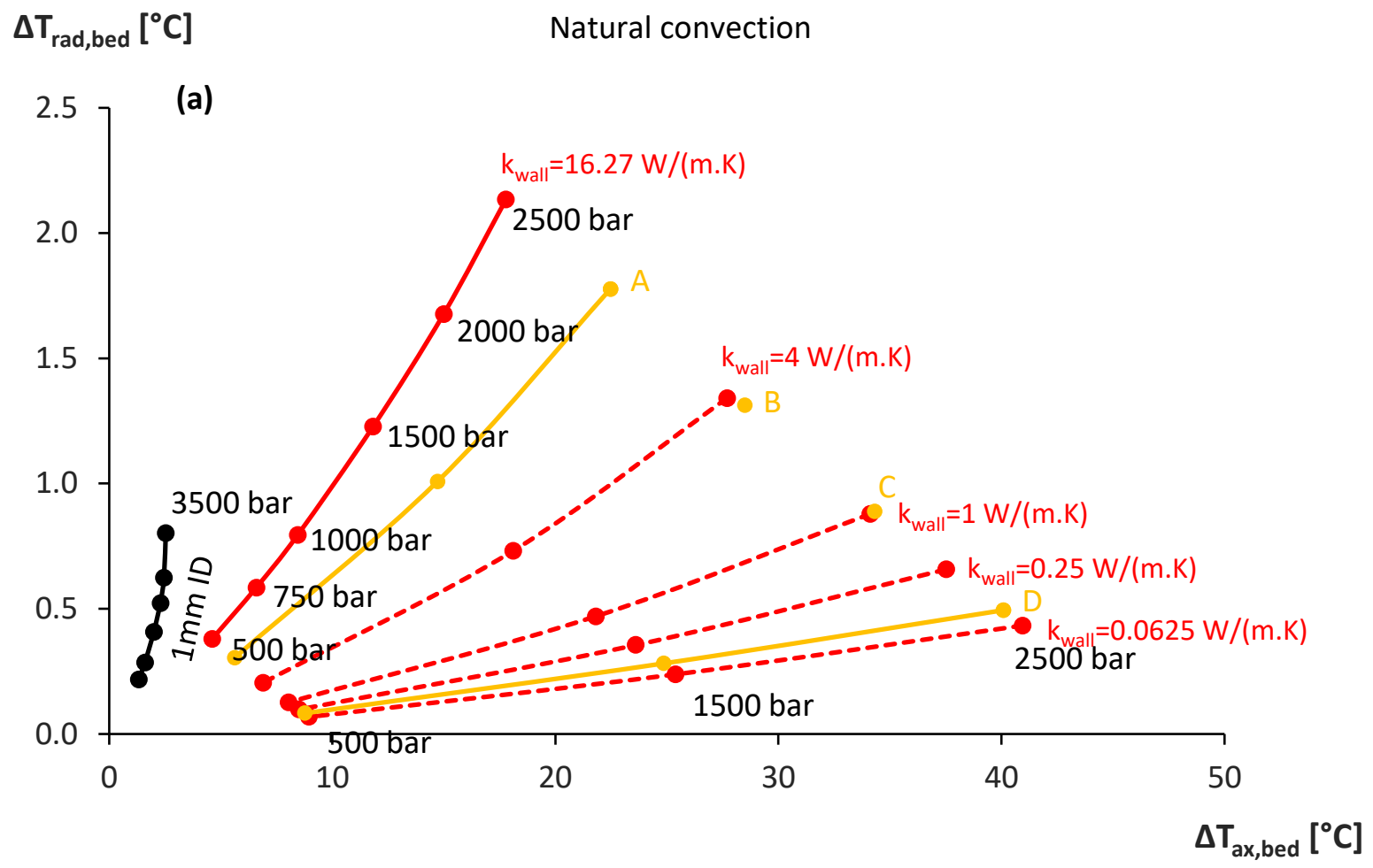

$\Delta \mathrm{T}_{\text {rad,bed }}\left[{ }^{\circ} \mathrm{C}\right]$

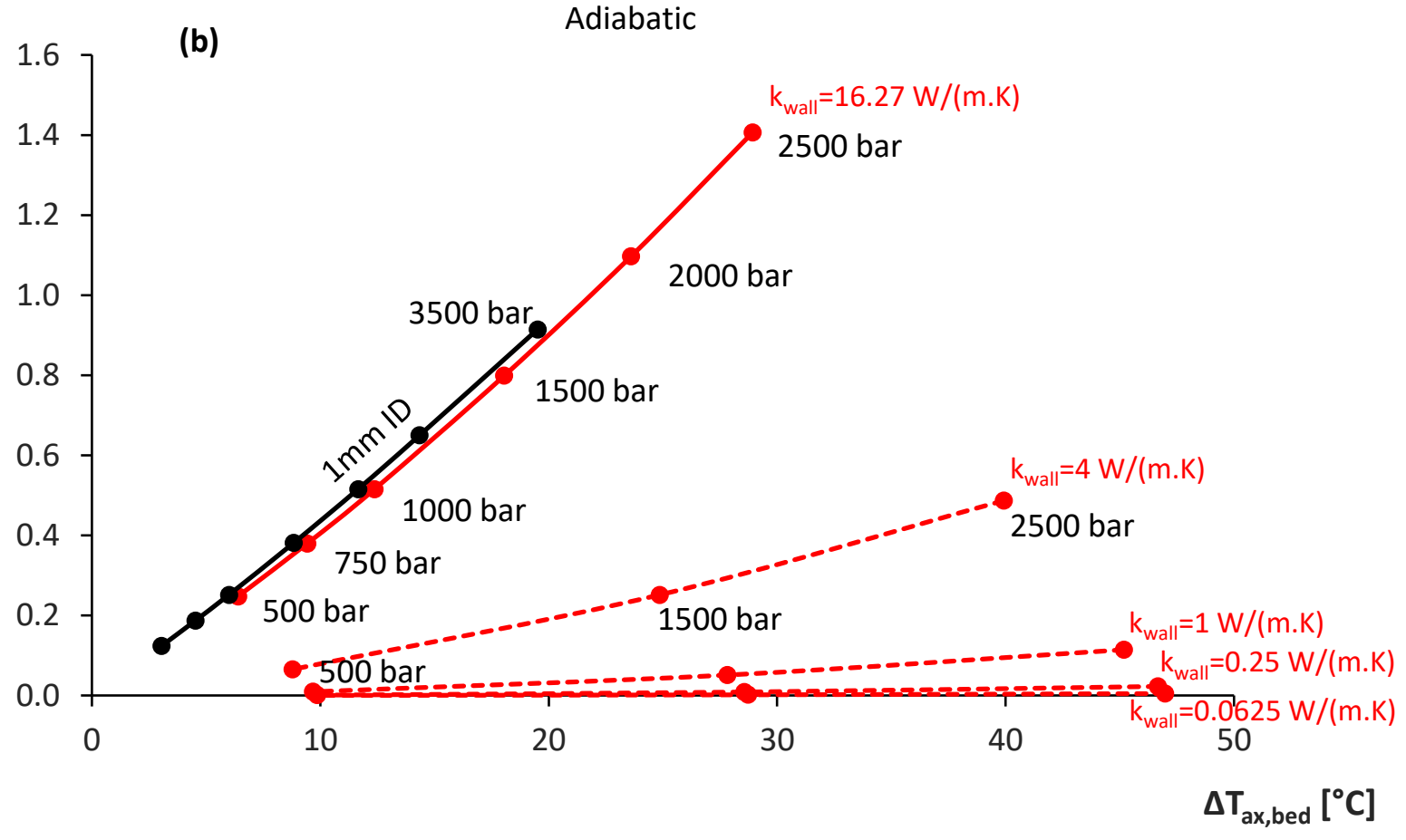




\section{Figure captions}

Figure 1. Unit cells of different ordered sphere packings (a-c), unit cell of the random sphere packing considered in Section 3.2 (d) and unit cells of the tetrahedral skeleton model geometries considered in Sections 3.1 and $3.2(\mathbf{e}, \mathbf{f})$. All sphere and branch radii are $1.00 \mu \mathrm{m}$. The corresponding unit cell lengths (in direction of the temperature gradient) and porosities $(\varepsilon)$ are indicated in the figure. Core material: black, porous zone: grey, mobile zone: transparent blue. In case of fully porous structures, the core material was assigned the same properties as the porous zone (shell).

Figure 2. Effective conductivity for porous layers made up of TSM structures $(\bullet)$ or inversed TSM structures $(\diamond)$, for a range of porosities and different mobile phase conductivities. Red cubes ( $\square$ ) are FCC, BCC, SC packings at closest packing porosity and a random packing $\left(\varepsilon_{e}=0.39\right)$ for $k_{m}=0.21 \mathrm{~W} /(\mathrm{m} . \mathrm{K})$. Blue cubes $(\square)$ are same packings with $\mathrm{k}_{\mathrm{m}}=0.58 \mathrm{~W} /(\mathrm{m} . \mathrm{K})$.

Figure 3. Flow-dependency of relative effective conductivity $\left(k_{\text {eff }} / k_{\text {eff, } u=0}\right)$ of a random packing of fully porous spherical particles $\left(\varepsilon_{\mathrm{e}}=0.39\right)$. Conditions: $\mathrm{k}_{\mathrm{m}}=0.58 \mathrm{~W} /(\mathrm{m} . \mathrm{K}), \mathrm{k}_{\mathrm{pz}}=0.80 \mathrm{~W} /(\mathrm{m} . \mathrm{K})$. The dashed lines indicates $k_{\text {eff }} / k_{\text {eff, } u=0}=1$ (i.e. no influence of convection).

Figure 4. Effective conductivity $\left(k_{\text {eff }}\right)$ of packed beds of spheres (perfectly ordered fcc-packing with $\varepsilon_{\mathrm{e}}=0.24$ (a) and random packing with $\varepsilon_{\mathrm{e}}=0.39$ (b)). Both fully porous (black data) and core-shell (gray data) particles are considered. Conditions: $\mathrm{k}_{\mathrm{m}}=0.58 \mathrm{~W} /(\mathrm{m} . \mathrm{K}), \mathrm{k}_{\mathrm{SiO}_{2}}=1.4 \mathrm{~W} /(\mathrm{m} . \mathrm{K}), \mathrm{krO}_{2}=2 \mathrm{~W} /(\mathrm{m} . \mathrm{K}), \mathrm{k}_{\mathrm{Al}_{2} \mathrm{O}_{3}}=40 \mathrm{~W} /(\mathrm{m} . \mathrm{K})$, $\mathrm{k}_{\mathrm{Cu}}=400 \mathrm{~W} /(\mathrm{m} \cdot \mathrm{K})$.

Figure 5. Effective conductivity ( $k_{\text {eff }}$ ) of monolithic beds (TSM-packing with $\varepsilon_{e}=0.39$ (a), TSM-packing with $\varepsilon_{\mathrm{e}}=0.60$ (b)). Both fully porous and core-shell monoliths are considered (as indicated in figure).

Conditions: $\mathrm{k}_{\mathrm{m}}=0.58 \mathrm{~W} /(\mathrm{m} . \mathrm{K}), \mathrm{k}_{\mathrm{SiO}_{2}}=1.4 \mathrm{~W} /(\mathrm{m} . \mathrm{K}), \mathrm{k}_{\mathrm{Al}_{2} \mathrm{O}_{3}}=40 \mathrm{~W} /(\mathrm{m} . \mathrm{K}), \mathrm{k}_{\mathrm{Cu}}=400 \mathrm{~W} /(\mathrm{m} . \mathrm{K})$. The curve representing the data of zirconia core particles, coincides with the curve of the silica core case and was left out.

Figure 6. Effective conductivity ( $k_{\text {eff }}$ ) in a random packing of core-shell particles with varying core conductivity $k_{\text {core }}$ for pure water $\left(k_{m}=0.61 \mathrm{~W} /(m . K), \square\right)$, pure $A C N\left(k_{m}=0.19 \mathrm{~W} /(\mathrm{m} . \mathrm{K}), \Delta\right)$ and a $40 / 60(\mathrm{v} \% / \mathrm{v} \%) \mathrm{ACN} / \mathrm{H}_{2} \mathrm{O}$ mixture $\left(\mathrm{k}_{\mathrm{m}}=0.41 \mathrm{~W} /(\mathrm{m} . \mathrm{K})\right.$, ○).

Figure 7. Temperature distribution profiles in a $50 \times 2.1 \mathrm{~mm}$ metal tubing column operated at $2500 \mathrm{bar}$ for (a) isothermal, (b) adiabatic and (c) natural convection boundary conditions imposed the outer column 
walls. Flow rate $=0.5 \mathrm{~mL} / \mathrm{min}$, mobile phase=pure water. Arrows in (a) define the difference between $\Delta \mathrm{T}_{\mathrm{ax}, \text { bed }}$ and $\Delta \mathrm{T}_{\mathrm{ax}, \mathrm{col}}$ used in the text. Arrows in (c) indicate the main column dimensions (drawing to scale).

Figure 8. Plots of $\Delta \mathrm{T}_{\text {rad,bed }}$ as a function of (a) $\Delta \mathrm{T}_{\mathrm{ax}, \mathrm{col}}$ and (b) $\Delta \mathrm{T}_{\mathrm{ax}, \text { bed }}$ in a $2.1 \times 50 \mathrm{~mm}$ metal tubing column operated at different column pressures (500, 750, 1000, 1500, 2000 and 2500bar) with a 40/60(v\%/v\%) $\mathrm{ACN} / \mathrm{H}_{2} \mathrm{O}$ mixture and $\mathrm{k}_{\text {eff }}=0.59 \mathrm{~W} /(\mathrm{m} . \mathrm{K})$. Three different thermal boundary conditions as indicated in figure: isothermal, adiabatic and natural convection (still-air). Flow rate $=0.5 \mathrm{~mL} / \mathrm{min}$ for adiabatic case. Bed permeabilities of the adiabatic data points were also used for the corresponding (same inlet pressure) natural convection and isothermal points. Different column inlet pressures relating to the different data points are indicated in figure and follow the same order for all curves.

Figure 9. Effect of liquid composition on plots of $\Delta \mathrm{T}_{\text {rad,bed }}$ as a function of $\Delta \mathrm{T}_{\mathrm{ax}, \text { bed }}$ in a $2.1 \times 50 \mathrm{~mm}$ metal tubing column operated at different column pressures (500, 750, 1000, 1500, 2000 and 2500bar) for (a) natural convection (still-air) and (b) adiabatic boundary conditions. Considered liquids: pure water ( $\square$ ), pure $\mathrm{ACN}(\Delta)$ and a $40 / 60(\mathrm{v} \% / \mathrm{v} \%) \mathrm{ACN} / \mathrm{H}_{2} \mathrm{O}$ mixture (๑). Flow rate $=0.5 \mathrm{~mL} / \mathrm{min}$ for every pressure considered for the $\mathrm{ACN} / \mathrm{H}_{2} \mathrm{O}$ mixture under adiabatic conditions. Flow rates for natural convection conditions and for pure water and $\mathrm{ACN}$ changed in relation to their different viscosity (see text for details). Values for $\mathrm{k}_{\text {eff: }} 0.77 \mathrm{~W} /(\mathrm{m} . \mathrm{K})(\square), 0.37 \mathrm{~W} /(\mathrm{m} . \mathrm{K})(\Delta)$ and $0.59 \mathrm{~W} /(\mathrm{m} . \mathrm{K})(\odot)$.

Figure 10. Evolution of $\Delta T_{\text {rad,bed }}$ as a function of the column pressure drop for natural convection (full symbols) and adiabatic (open symbols) boundary conditions. Considered liquids: pure water ( $\square$ ), pure ACN $\left({ }^{-}\right.$) and a 40/60(v\%/v\%) $\mathrm{ACN} / \mathrm{H}_{2} \mathrm{O}$ mixture (O). (same data as in figure 9, different representation)

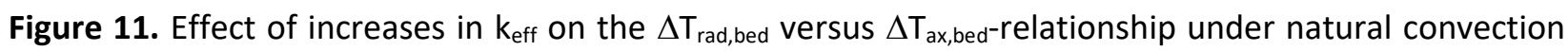
(still air) conditions for (a) a 40/60 ACN/water-mixture and (b) pure ACN. Different column inlet pressures are indicated in figure and follow the same order for all curves.

Figure 12. Effect of the conductivity of the column tube wall $\left(k_{\text {wall }}\right)$ on the $\Delta T_{\text {rad,bed }}$ versus $\Delta T_{\text {ax,bed }}{ }^{-}$ relationship under (a) natural convection (still air) and (b) adiabatic conditions for the 40/60 ACN/watermixture. Red data represent single-material columns with either a regular wall conductivity $\left(k_{\text {wall }}=k_{\text {stainless }}\right.$ steel $=16.27 \mathrm{~W} /(\mathrm{m} . \mathrm{K})$, solid line) or a lowered wall conductivity (dashed lines). Yellow data represent a stainless steel column $\left(k_{\text {wall }}=16.27 \mathrm{~W} /(\mathrm{m} . \mathrm{K})\right)$ with extra internal coating (100 $\mu \mathrm{m}$ thickness) with different thermal conductivities (A: $k_{\text {coat }}=0.25 \mathrm{~W} /(\mathrm{m} . \mathrm{K}), \mathrm{B}: \mathrm{k}_{\text {coat }}=0.0625 \mathrm{~W} /(\mathrm{m} . \mathrm{K}), \mathrm{C}: \mathrm{k}_{\text {coat }}=0.0156 \mathrm{~W} /(\mathrm{m} . \mathrm{K}), \mathrm{D}$ : $\left.\mathrm{k}_{\text {coat }}=0.0039 \mathrm{~W} /(\mathrm{m} . \mathrm{K})\right)$. Black data represent a regular column with $1 \mathrm{~mm} I \mathrm{D}$. Different column inlet pressures are indicated in figure and are the same for all curves, with one extra high pressure (3500bar) in case of the $1 \mathrm{~mm}$ ID column. 


\title{
Supplementary information for:
}

\author{
A Multiscale Modelling Study on the Sense and Nonsense of Thermal Conductivity \\ Enhancement of Liquid Chromatography Packings and Other Potential Solutions for Viscous \\ Heating Effects \\ Sander Deridder, Wim Smits, Ken Broeckhoven, Gert Desmet ${ }^{(*)}$
}

Vrije Universiteit Brussel, Department of Chemical Engineering, Pleinlaan 2, B-1050 Brussels, Belgium

$(*)$ Corresponding author

Pleinlaan 2, B-1050 Brussels, Belgium

Tel.: +32 (0) 2629 3251, Fax.: +32 (0) 26293248

E-mail: gedesmet@vub.be 

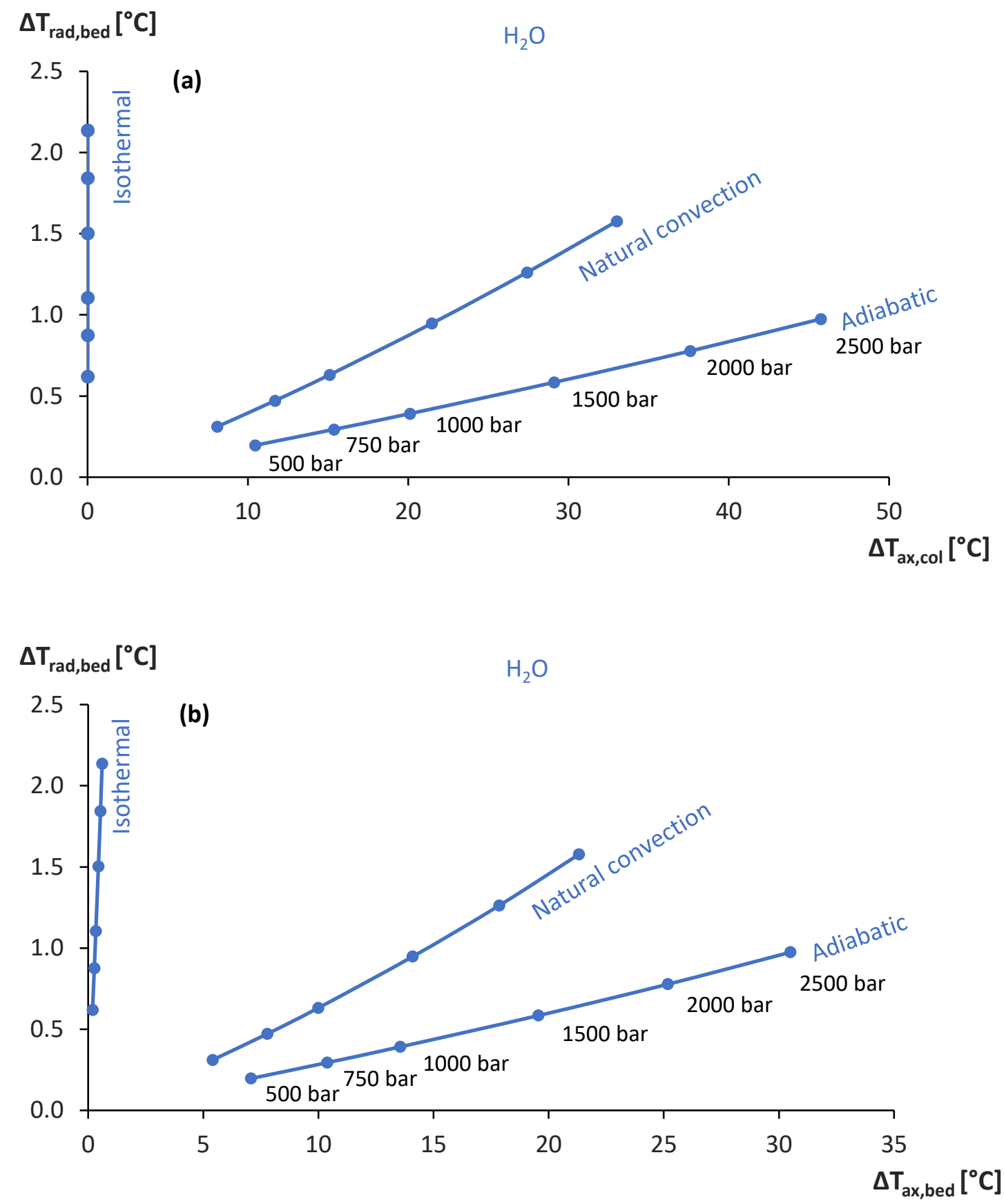

Figure S1. Plots of $\Delta \mathrm{T}_{\text {rad,bed }}$ as a function of (a) $\Delta \mathrm{T}_{\mathrm{ax}, \mathrm{col}}$ and (b) $\Delta \mathrm{T}_{\mathrm{ax}, \mathrm{bed}}$ in a $2.1 \times 50 \mathrm{~mm}$ metal tubing column operated at different column pressures $\left(500,750,1000,1500,2000\right.$ and 2500 bar) with a pure $\mathrm{H}_{2} \mathrm{O}$ mobile phase and $k_{\text {eff }}=0.77 \mathrm{~W} /(\mathrm{m} . \mathrm{K})$. Three different thermal boundary conditions as indicated in figure: isothermal, adiabatic and natural convection (still-air). Flow rate $=0.5 \mathrm{~mL} / \mathrm{min}$ for adiabatic case. Bed permeabilities of the adiabatic data points were also used for the corresponding (same inlet pressure) natural convection and isothermal points. Different column inlet pressures are indicated in figure and are the same for all curves. 

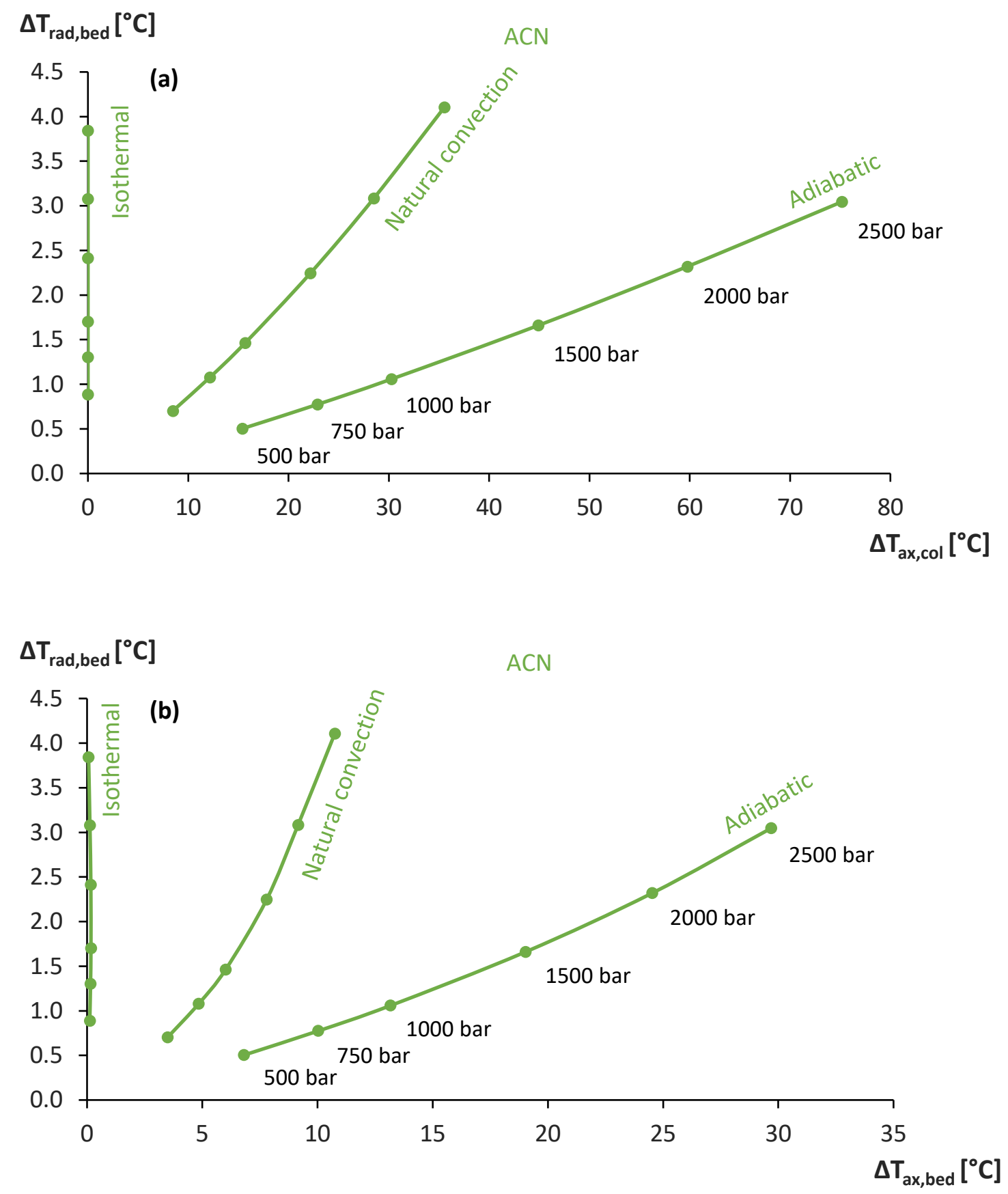

Figure S2. Plots of $\Delta \mathrm{T}_{\text {rad,bed }}$ as a function of (a) $\Delta \mathrm{T}_{\mathrm{ax}, \mathrm{col}}$ and (b) $\Delta \mathrm{T}_{\mathrm{ax}, \mathrm{bed}}$ in a $2.1 \times 50 \mathrm{~mm}$ metal tubing column operated at different column pressures $(500,750,1000,1500,2000$ and 2500bar) with a pure ACN mobile phase and $k_{\text {eff }}=0.37 \mathrm{~W} /(\mathrm{m} . \mathrm{K})$. Three different thermal boundary conditions as indicated in figure: isothermal, adiabatic and natural convection (still-air). Flow rate $=0.5 \mathrm{~mL} / \mathrm{min}$ for adiabatic case. Bed permeabilities of the adiabatic data points were also used for the corresponding (same inlet pressure) natural convection and isothermal points. Different column inlet pressures are indicated in figure and are the same for all curves. 
(a)
$\Delta \mathrm{T}_{\text {rad,bed }}\left[{ }^{\circ} \mathrm{C}\right]$
Natural convection

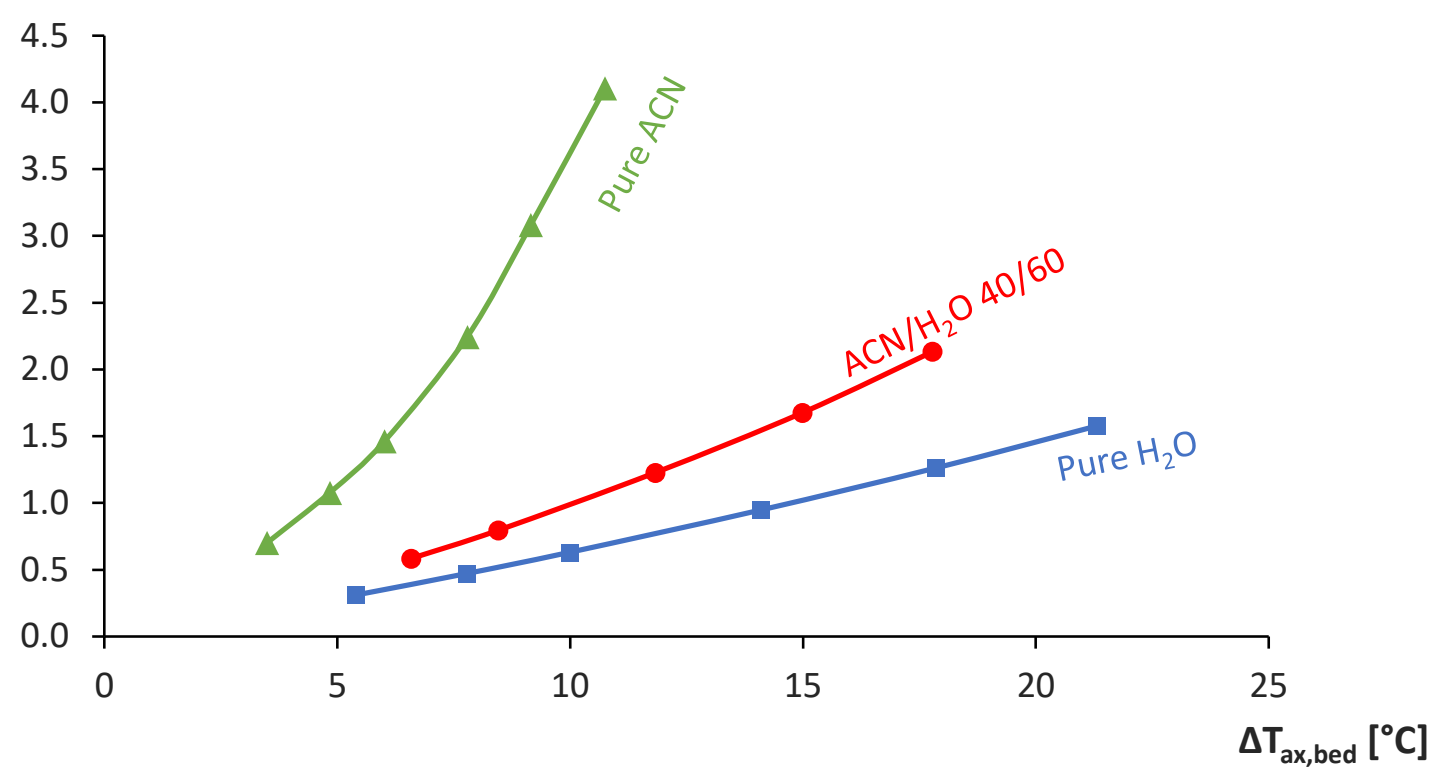

(b)
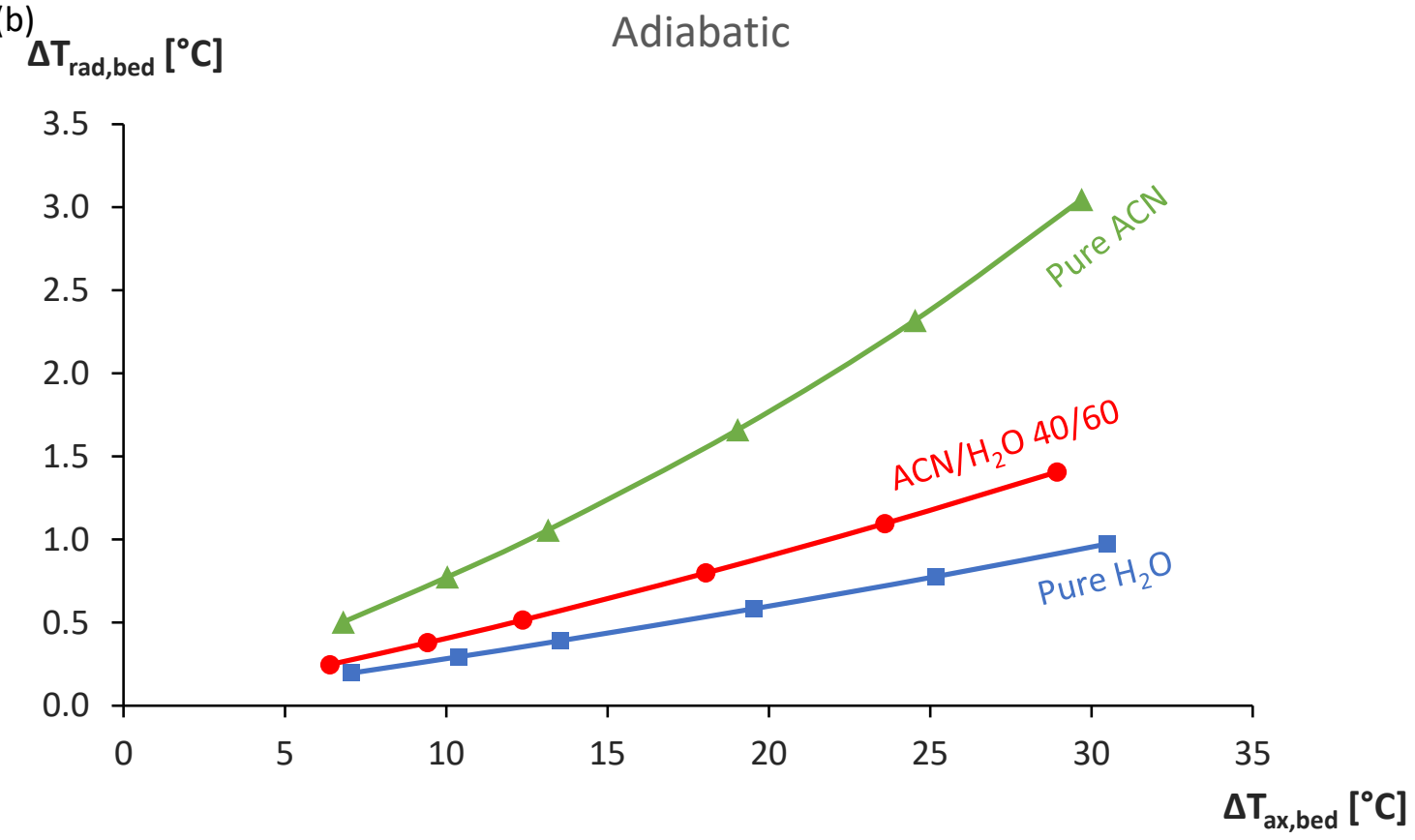

Figure S3. Effect of liquid composition on plots of $\Delta \mathrm{T}_{\text {rad,bed }}$ as a function of $\Delta \mathrm{T}_{\text {ax,bed }}$ in a $2.1 \times 50 \mathrm{~mm}$ metal tubing column operated at different column pressures (500, 750, 1000, 1500, 2000 and 2500bar) for (a) natural convection (still-air) and (b) adiabatic boundary conditions. Considered liquids: pure water ( $\square$ ), pure $\mathrm{ACN}(\triangle)$ and a $40 / 60(\mathrm{v} \% / \mathrm{v} \%) \mathrm{ACN} / \mathrm{H}_{2} \mathrm{O}$ mixture $(\bullet)$. Flow rate $=0.5 \mathrm{~mL} / \mathrm{min}$ under adiabatic conditions (for all inlet pressures considered and all three mobile phases). Flow rates for natural convection conditions changed in relation to their different viscosity. Values for keff: $0.77 \mathrm{~W} /(\mathrm{m} . \mathrm{K})(\square)$, $0.37 \mathrm{~W} /(\mathrm{m} . \mathrm{K})(\Delta)$ and $0.59 \mathrm{~W} /(\mathrm{m} . \mathrm{K})(\odot)$. 


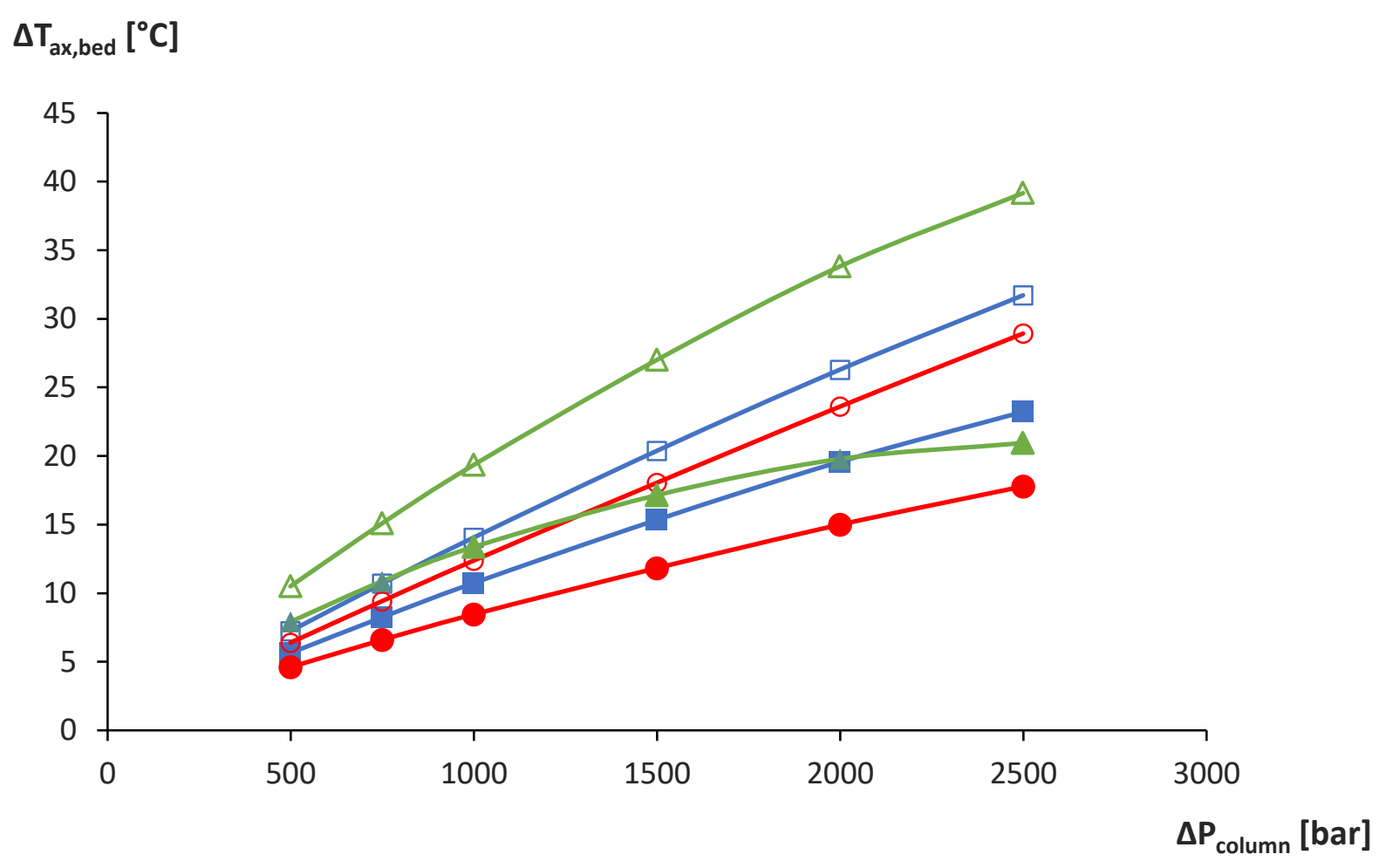

Figure S4. Evolution of $\Delta \mathrm{T}_{\mathrm{ax} \text {,bed }}$ as a function of the column pressure drop for natural convection (full symbols) and adiabatic (open symbols) boundary conditions. Considered liquids: pure water ( $\square$ ), pure ACN $(\triangle)$ and a $40 / 60(v \% / v \%) A C N / \mathrm{H}_{2} \mathrm{O}$ mixture (O). (same data as in figure 9, different representation) 